\title{
Um curso rápido de cálculo diferencial e integral para pré-universitários e calouros
}

\author{
Thyago Celso Santos Silva ${ }^{1} \&$ Paulo Peixoto ${ }^{2}$
}

(1) Universidade Federal de Pernambuco, Núcleo de Formação Docente. Av. Marielle Franco, S/N, Nova Caruaru, 55014-900, Caruaru, Pernambuco, Brasil. E-mail: celsothyago@gmail.com

(2) Universidade Federal de Pernambuco, Núcleo de Formação Docente. Av. Marielle Franco, S/N, Nova Caruaru, 55014-900, Caruaru, Pernambuco, Brasil. E-mail: paulo.peixoto@ufpe.br

Silva T.C.S. \& Peixoto P. (2020) Um curso rápido de cálculo diferencial e integral para pré-universitários e calouros. Pesquisa e Ensino em Ciências Exatas e da Natureza, 4:e1602. http://dx.doi.org/10.29215/pecen.v4i0.1602

Editor acadêmico:Francisco José de Andrade.Recebido:04 setembro 2020.Aceito:14 dezembro 2020.Publicado:30 dezembro 2020.

Resumo: Este texto consiste em um material didático voltado a estudantes prestes a iniciar sua graduação em física ou engenharia. Estamos convencidos de que um contato prévio com o cálculo diferencial e integral, em um nível adequado, é extremamente vantajoso para os calouros. Aplicações do cálculo à física são exploradas, e o texto inclui uma lista de exercícios, com respostas.

Palavras-chave: cálculo diferencial e integral, pré-universitários, aplicações do cálculo à física.

A short course in differential and integral calculus for pre-university students and freshmen

Abstract: This text is a didactic material designed for students about to begin their degree in physics or engineering. We are convinced that prior contact with differential and integral calculus, at an appropriate level, is of great benefit to freshmen. Applications of calculus in physics are explored, and the text includes a list of exercises, with answers.

Key words: differential and integral calculus, pre-university students, applications of calculus in physics.

\section{Introdução}

Dificilmente conseguiríamos enfatizar suficientemente a importância do cálculo diferencial e integral em cursos de graduação em física ou engenharia. Sem o cálculo não podemos avançar da física que estudamos no ensino médio para a física que estudamos já nos primeiros semestres desses cursos de graduação.

Em geral, os estudantes têm 3 ou 4 disciplinas obrigatórias de cálculo, e a primeira delas é, sem dúvida, a mais importante, porque é onde os conceitos fundamentais de limites, derivadas e integrais, e algumas de suas aplicações, são trabalhados pela primeira vez. Se os estudantes não conseguirem apreendê-los bem, terão sérias dificuldades nas demais disciplinas de cálculo, e nas de física. O problema é que a primeira disciplina de cálculo, em seu formato 


\section{Um curso rápido de cálculo diferencial e integral para pré-universitários e calouros}

padrão, não é nada fácil. Há muito conteúdo, e o professor pode conduzir suas aulas com um rigor matemático muito elevado, para uma primeira disciplina, dificultando a compreensão intuitiva do cálculo pelos estudantes. E, para complicar ainda mais, em muitas instituições a primeira disciplina de física que faz uso do cálculo é ofertada no mesmo semestre em que a primeira disciplina de cálculo. Daí, é comum que enquanto o professor de cálculo ainda está ensinando limites, o professor de física já está fazendo uso do conceito de derivada para calcular velocidades e acelerações instantâneas. Tudo isso pode deixar a vida do estudante bem difícil.

Estamos convencidos de que um contato prévio com o cálculo, desde que em um nível adequado, é extremamente vantajoso para os calouros, e não apenas para um melhor aproveitamento de sua primeira disciplina nesta área, mas também de sua primeira disciplina de física que faça uso do cálculo. Neste texto, oferecemos a esse público um material didático que pode ser usado individualmente ou para estudo em grupo. Aplicações à física são exploradas, e uma lista de exercícios, com respostas, constitui a seção final.

O único pré-requisito para este curso é uma boa formação em matemática e física ao nível do ensino médio 1

O texto está estruturado nas seguintes seções (além desta Introdução, da Conclusão, dos Agradecimentos e da Lista de Exercícios, ao final), que podem ser organizadas em três grupos:

\section{Grupo 1: Limites}

\section{Limites}

\section{Grupo 2: Derivadas}

A derivada

Aplicações da derivada

\section{Grupo 3: Integrais}

Antiderivadas ou primitivas

A integral definida

Aplicações da integral definida

A integral indefinida

Por fim, queremos dizer que há no mercado um grande número de livros de cálculo diferencial e integral. Cada um deles tem seu sabor, sua personalidade, sua proposta. $\mathrm{Na}$ elaboração deste texto, fizemos uso de muitos títulos, mas optamos por não apresentá-los aqui porque não exploramos outros tantos, e não queremos ser injustos com seus autores - inclusive nacionais - deixando de divulgar seus livros. Torcemos para que seu professor ou sua professora de cálculo trabalhe com livros de que você goste.

\section{Limites}

Quando aplicamos o cálculo à física e às demais áreas do conhecimento, quase sempre estamos envolvidos com derivadas ou integrais. Mas antes de estudarmos esses assuntos, precisamos aprender algumas coisas básicas sobre limites de funções.

\footnotetext{
${ }^{1}$ Em princípio, os conteúdos de matemática e física do primeiro ano são suficientes como pré-requisitos para este curso, mas um estudante do segundo ano pode ter ainda pouca maturidade para acompanhar este material; mas há exceções.
} 


\section{Um curso rápido de cálculo diferencial e integral para pré-universitários e calouros}

\section{Limites de funções - uma introdução}

Seja $f$ uma função de $x$, e seja $a$ um número real. Se, quando $x$ tende a $a, f(x)$ tende a $L$, escrevemos

$$
\lim _{x \rightarrow a} f(x)=L,
$$

e lemos: "o limite de $f(x)$, quando $x$ tende a $a$, é $L$ ".

Exemplo 1: Observe a figura a seguir (Fig.1), que apresenta o gráfico de $f(x)=x^{2}$ para $x \geq 0$. Ela mostra claramente que quando $x$ tende a 3 , pela esquerda $(\rightarrow 3)$ ou pela direita $(3 \leftarrow), f(x)$ tende a 9. Assim, podemos escrever:

$$
\lim _{x \rightarrow 3} f(x)=\lim _{x \rightarrow 3} x^{2}=9 .
$$

Ora, como $f(3)=9$, e como $f$ é uma função "bem comportada", então é claro que quando $x$ tende a 3, $f(x)$ tende a 9. Você pode perguntar: o que há de mais nisso? Aguarde. Vamos ver a seguir um exemplo bem mais interessante.

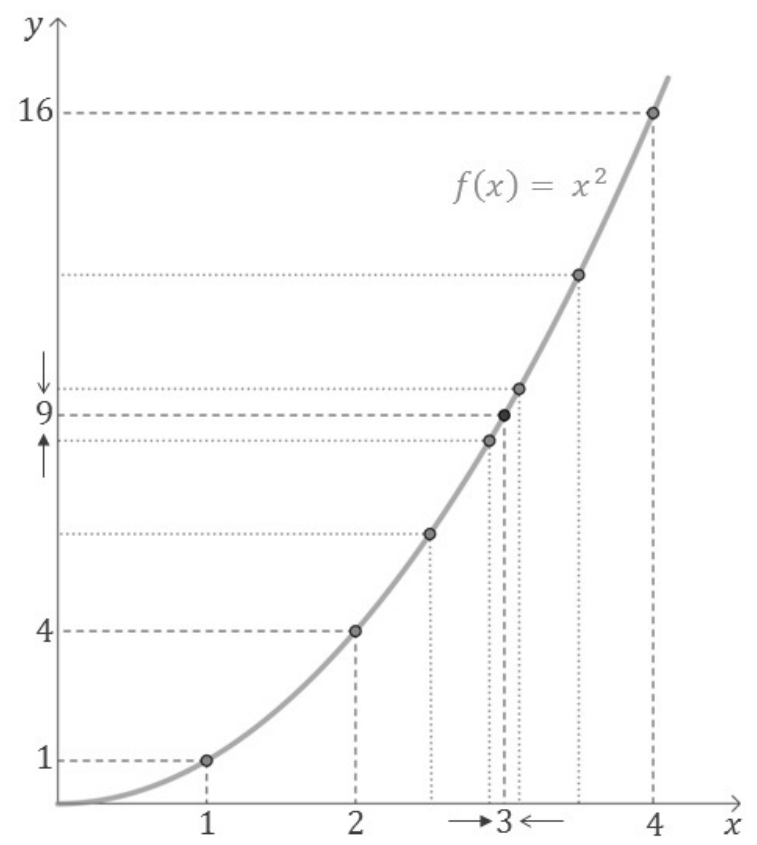

Figura 1: Gráfico de $f(x)=x^{2}$ para $x \geq 0$. Observe que quando $x$ tende a 3, pela esquerda ou pela direita, $f(x)$ tende a 9, e assim escrevemos: $\lim _{x \rightarrow 3} f(x)=9$.

Exemplo 2: Seja $f(x)=\left(x^{2}-9\right) /(x-3)$. Temos:

$$
\lim _{x \rightarrow 3} f(x)=\lim _{x \rightarrow 3} \frac{x^{2}-9}{x-3} .
$$

O problema é que $f(x)$ não está definida para $x=3$, pois teríamos $f(3)=0 / 0$, e $0 / 0$ não tem significado algum. Contudo, ao escrevermos $\lim _{x \rightarrow 3} f(x)$, devemos ter em mente o valor para o qual $f(x)$ tende, quando $x$ tende a 3, não o valor de $f(x)$ para $x=3$ (que, neste caso, nem existe). Esse valor para o qual $f(x)$ tende quando $x$ tende a 3 (supondo que esse valor existe) é o limite de $f(x)$, quando $x$ tende a 3. Mas como calcular esse limite? Há uma forma. Veja:

$$
\lim _{x \rightarrow 3} f(x)=\lim _{x \rightarrow 3} \frac{x^{2}-9}{x-3}=\lim _{x \rightarrow 3} \frac{(x+3)(x-3)}{x-3},
$$




\section{Um curso rápido de cálculo diferencial e integral para pré-universitários e calouros}

pois $x^{2}-9=(x+3)(x-3)$. Como não estamos fazendo $x=3$, mas apenas fazendo $x$ tender a 3 , podemos dividir $x-3$ por $x-3$, e com isso obtemos:

$$
\lim _{x \rightarrow 3} f(x)=\lim _{x \rightarrow 3} \frac{(x+3)(x-3)}{x-3}=\lim _{x \rightarrow 3}(x+3)=6,
$$

pois, é claro, quando $x$ tende a $3, x+3$ tende a 6 . Portanto, quando $x$ tende a $3, f(x)=\left(x^{2}-\right.$ $9) /(x-3)$ tende a 6 , embora esta função não esteja definida para $x=3$. Bacana, não é? Usando uma calculadora, experimente calcular $\left(x^{2}-9\right) /(x-3)$ para valores de $x$ muito próximos de 3 , como $x=2,9$ ou 2,99 ou 3,1 ou 3,01. Você verá que quanto mais próximo de 3 for o valor de $x$, mais próximo de 6 será o valor de $\left(x^{2}-9\right) /(x-3)$. Mas para $x=3$, a calculadora emitirá uma mensagem de erro, pois, como você já sabe, " $0 / 0$ " não tem significado algum. Perceba que o gráfico de $f(x)=\left(x^{2}-9\right) /(x-3)$ é igual ao gráfico da função $g(x)=x+3$, mas retirado deste o ponto $(3,6)$.

Agora, vamos discutir com mais cuidado o que significa $f(x)$ tender a L quando $x$ tende $a$ a, ao escrevermos

$$
\lim _{x \rightarrow a} f(x)=L .
$$

É que existe uma armadilha nessa ideia, à qual devemos estar atentos. Em primeiro lugar, "tender a" é diferente de "se aproximar de". Ao fazermos $x$ tender a 3 pela esquerda, por exemplo (veja a Fig.11), também fazemos o valor de $x$ se aproximar cada vez mais de 3,1, concorda? Contudo, nesse processo, a diferença entre 3,1 e $x$ é sempre maior que 0,1, percebe? Vamos introduzir alguns números. Tomemos, de início, $x=2,9$. Daí, mudemos o valor de $x$ para 2,99, e então para 2,999, 2,9999, e assim por diante. Estamos fazendo $x$ tender a 3, mas também estamos fazendo o valor de $x$ se aproximar não só de 3, mas também, por exemplo, de 3,1. Afinal, concordaremos que 2,999 está mais próximo de 3,1 que 2,99. Então, podemos pensar "tender a" como "se aproximar de", mas "sem restrição". Tenha isso em mente ao ler que a igualdade $\lim _{x \rightarrow a} f(x)=L$ significa que quando $x$ tende a $a, f(x)$ tende a $L$. Talvez seja interessante reler os Exemplos 1 e 2, concluída esta discussão.

Agora, vamos explorar mais um exemplo.

Exemplo 3: A posição $s$ de uma partícula varia com o tempo $t$ de acordo com a função $s(t)=$ $2 t^{3}$, com $s$ em metros e $t$ em segundos. Vamos calcular:

a) a velocidade média da partícula entre os instantes $t_{1}$ e $t_{2}$.

b) a velocidade instantânea da partícula no instante $t_{1}$.

c) a velocidade instantânea da partícula em um instante $t$ qualquer.

Vejamos: a)

$$
v_{\text {méd }}=\frac{\Delta s}{\Delta t}=\frac{s\left(t_{2}\right)-s\left(t_{1}\right)}{t_{2}-t_{1}}=\frac{2 t_{2}^{3}-2 t_{1}^{3}}{t_{2}-t_{1}},
$$

no SI (Sistema Internacional de Unidades). Por exemplo, com $t_{1}=3 \mathrm{~s} \mathrm{e} t_{2}=5 \mathrm{~s}$ obtemos $v_{\text {méd }}=$ $98 \mathrm{~m} / \mathrm{s}$.

b) Inicialmente, convém reescrevermos a expressão $\left(s\left(t_{2}\right)-s\left(t_{1}\right)\right) /\left(t_{2}-t_{1}\right)$ para a velocidade média da partícula entre os instantes $t_{1}$ e $t_{2}$ da seguinte forma:

$$
v_{\text {méd }}=\frac{s\left(t_{1}+\Delta t\right)-s\left(t_{1}\right)}{\Delta t} .
$$

Esta expressão está correta porque $\Delta t=t_{2}-t_{1}$ e, portanto, $t_{2}=t_{1}+\Delta t$. Estamos interessados no valor para o qual a razão $\left(s\left(t_{1}+\Delta t\right)-s\left(t_{1}\right)\right) / \Delta t$ tende quando $\Delta t$ tende a 0 . Esse limite é a velocidade (instantânea) da partícula no instante $t_{1}$ :

$$
v\left(t_{1}\right)=\lim _{\Delta t \rightarrow 0} \frac{s\left(t_{1}+\Delta t\right)-s\left(t_{1}\right)}{\Delta t} .
$$


Como, neste exemplo, $s(t)=2 t^{3}$ (no SI), temos:

$$
\begin{aligned}
v\left(t_{1}\right) & =\lim _{\Delta t \rightarrow 0} \frac{s\left(t_{1}+\Delta t\right)-s\left(t_{1}\right)}{\Delta t}=\lim _{\Delta t \rightarrow 0} \frac{2\left(t_{1}+\Delta t\right)^{3}-2 t_{1}^{3}}{\Delta t} \\
& =\lim _{\Delta t \rightarrow 0} \frac{2\left[t_{1}^{3}+3 t_{1}^{2} \Delta t+3 t_{1}(\Delta t)^{2}+(\Delta t)^{3}\right]-2 t_{1}^{3}}{\Delta t} \\
& =\lim _{\Delta t \rightarrow 0} \frac{2 t_{1}^{3}+6 t_{1}^{2} \Delta t+6 t_{1}(\Delta t)^{2}+2(\Delta t)^{3}-2 t_{1}^{3}}{\Delta t} \\
& =\lim _{\Delta t \rightarrow 0}\left[6 t_{1}^{2}+6 t_{1} \Delta t+2(\Delta t)^{2}\right]=6 t_{1}^{2},
\end{aligned}
$$

no SI. Por exemplo, com $t_{1}=3 \mathrm{~s}$ obtemos $v(3 \mathrm{~s})=54 \mathrm{~m} / \mathrm{s}$. Isso significa que se a partícula se mantivesse com esta velocidade, ela percorreria 54 metros a cada segundo.

c) Neste exemplo, $t_{1}$ representa um instante específico. Mas como ele pode assumir qualquer valor, podemos usar " $t$ " em vez de $t_{1}$ no desenvolvimento acima para o cálculo da velocidade instantânea. Com isso, obtemos a velocidade da partícula deste exemplo em função do tempo: $v(t)=6 t^{2}$, no SI.

A partir deste exemplo, podemos definir a velocidade instantânea $v(t)$ de uma partícula, no instante $t$, como

$$
v(t)=\lim _{\Delta t \rightarrow 0} \frac{s(t+\Delta t)-s(t)}{\Delta t}
$$

sendo $s(t)$ a função horária da posição da partícula. Procure criar a maior intimidade possível com este limite. Não se trata de memorizá-lo, mas de compreendê-lo. Esse tipo de limite tem um nome especial: derivada.

Sugerimos que você resolva agora os Exercícios 1 a 4 da lista de exercícios (seção final deste texto).

\section{Propriedades básicas de limites}

Sejam $f$ e $g$ funções de $x$, e $c$ uma constante. Vamos supor que os limites de $f(x)$ e $g(x)$, quando $x$ tende a $a$, existem. $2^{2}$ Temos as seguintes propriedades:

\section{Propriedade 1:}

$$
\lim _{x \rightarrow a}[f(x)+g(x)]=\lim _{x \rightarrow a} f(x)+\lim _{x \rightarrow a} g(x) .
$$

(Costuma-se dizer: o limite da soma é a soma dos limites.)

\section{Propriedade 2:}

$$
\lim _{x \rightarrow a}[c f(x)]=c \lim _{x \rightarrow a} f(x) .
$$

(Costuma-se dizer: um fator constante pode ser movido através do símbolo de limite.)

Propriedade 3:

$$
\lim _{x \rightarrow a}[f(x) g(x)]=\left[\lim _{x \rightarrow a} f(x)\right]\left[\lim _{x \rightarrow a} g(x)\right] .
$$

(Costuma-se dizer: o limite do produto é o produto dos limites.)

Propriedade 4:

$$
\lim _{x \rightarrow a} \frac{f(x)}{g(x)}=\frac{\lim _{x \rightarrow a} f(x)}{\lim _{x \rightarrow a} g(x)}, \text { desde que } \lim _{x \rightarrow a} g(x) \neq 0 .
$$

\footnotetext{
${ }^{2}$ É importante você saber que nem sempre existe o limite de uma função $h(x)$, quando $x$ tende a um certo número $a$. Por exemplo, não existe o limite de $h(x)=1 / x$ quando $x$ tende a 0 . Você verá muito mais sobre isso em sua primeira disciplina de cálculo na universidade.
} 


\section{Um curso rápido de cálculo diferencial e integral para pré-universitários e calouros}

(Costuma-se dizer: o limite do quociente é o quociente dos limites, desde que o limite do denominador não seja igual a zero.)

\section{Propriedade 5:}

$$
\lim _{x \rightarrow a} c=c .
$$

(Costuma-se dizer: o limite de uma constante é igual à própria constante.)

\section{Propriedade 6:}

$$
\lim _{x \rightarrow a} x=a .
$$

Mais adiante faremos uso dessas propriedades básicas. São propriedades intuitivas, em nossa opinião. Por exemplo, sejam $f(x)=3 x^{2}+1$ e $g(x)=x^{3}-x$. Quando $x$ tende a $2, f(x)$ tende a 13 e $g(x)$ tende a 6; então é razoável esperar que o produto $f(x) g(x)$ tenda a $13 \cdot 6(=78)$, não acha? Para checar, vamos calcular $\lim _{x \rightarrow 2}\left[\left(3 x^{2}+1\right)\left(x^{3}-x\right)\right]$ sem o uso da propriedade 3 :

$$
\lim _{x \rightarrow 2} \underbrace{\left[\left(3 x^{2}+1\right)\left(x^{3}-x\right)\right]}_{3 x^{5}-2 x^{3}-x}=\lim _{x \rightarrow 2}\left(3 x^{5}-2 x^{3}-x\right)=3 \cdot 2^{5}-2 \cdot 2^{3}-2=78 \text {. }
$$

Obtivemos o mesmo resultado, como já esperávamos.

\section{Explorando um pouco mais o conceito de limite}

\section{Tentando preencher um círculo com triângulos, e calculando sua área!}

Você deve saber que a razão entre o comprimento $C$ de uma circunferência e o seu diâmetro $D$ é o número irracional $\pi$. Isso vale para qualquer circunferência, seja qual for o seu diâmetro. Ou seja, diferentes circunferências podem ter diferentes diâmetros e diferentes comprimentos, mas a razão $C / D$ é a mesma, sempre. Como o diâmetro de uma circunferência é o dobro de seu raio $R$, temos:

$$
\frac{C}{D}=\pi \Longrightarrow \frac{C}{2 R}=\pi \Longrightarrow C=2 \pi R .
$$

E quanto à área $A_{C}$ de um círculo de raio $R$ ? Você certamente sabe que $A_{C}=\pi R^{2}$, mas como obter essa expressão? Como veremos, uma possibilidade é usarmos o conceito de limite. Podemos tentar preencher um círculo com triângulos, como ilustrado na Fig.2. Observe que quanto mais triângulos usamos, mais a área total dos triângulos se aproxima da área do círculo. Procure visualizar o seguinte: quando o número $n$ de triângulos usados tende a infinito, a área total dos triângulos tende à área do círculo. Assim, a área do círculo é o limite da área total dos triângulos, quando o número de triângulos tende a infinito. Este é um ponto crucial da discussão. É claro que jamais conseguiríamos preencher exatamente um círculo (cujo contorno é curvo) com triângulos (cujos contornos são formados por segmentos de reta). Mas não precisamos! Basta enxergarmos que a área do círculo é o limite para o qual tende a área total dos triângulos, quando o número de triângulos tende a infinito. Calculando esse limite, teremos uma expressão exata para a área do círculo.

Vamos às contas. Com $n$ triângulos, a área total dos triângulos é $n b h / 2$, em que $b$ é a medida da base e $h$ é a medida da altura de cada triângulo. Quando $n \rightarrow \infty$, podemos ver (observe a figura) que $h \rightarrow R$ e $n b \rightarrow 2 \pi R$. Logo, quando $n$ tende a infinito, a área total dos triângulos, $n b h / 2$, tende a $2 \pi R \cdot R / 2$, ou seja, a $\pi R^{2}$, que é a área do círculo. Muito bacana, não acha? É interessante observar que quando $n \rightarrow \infty, b \rightarrow 0$, mas o produto $n b$ tende a $2 \pi R$. 


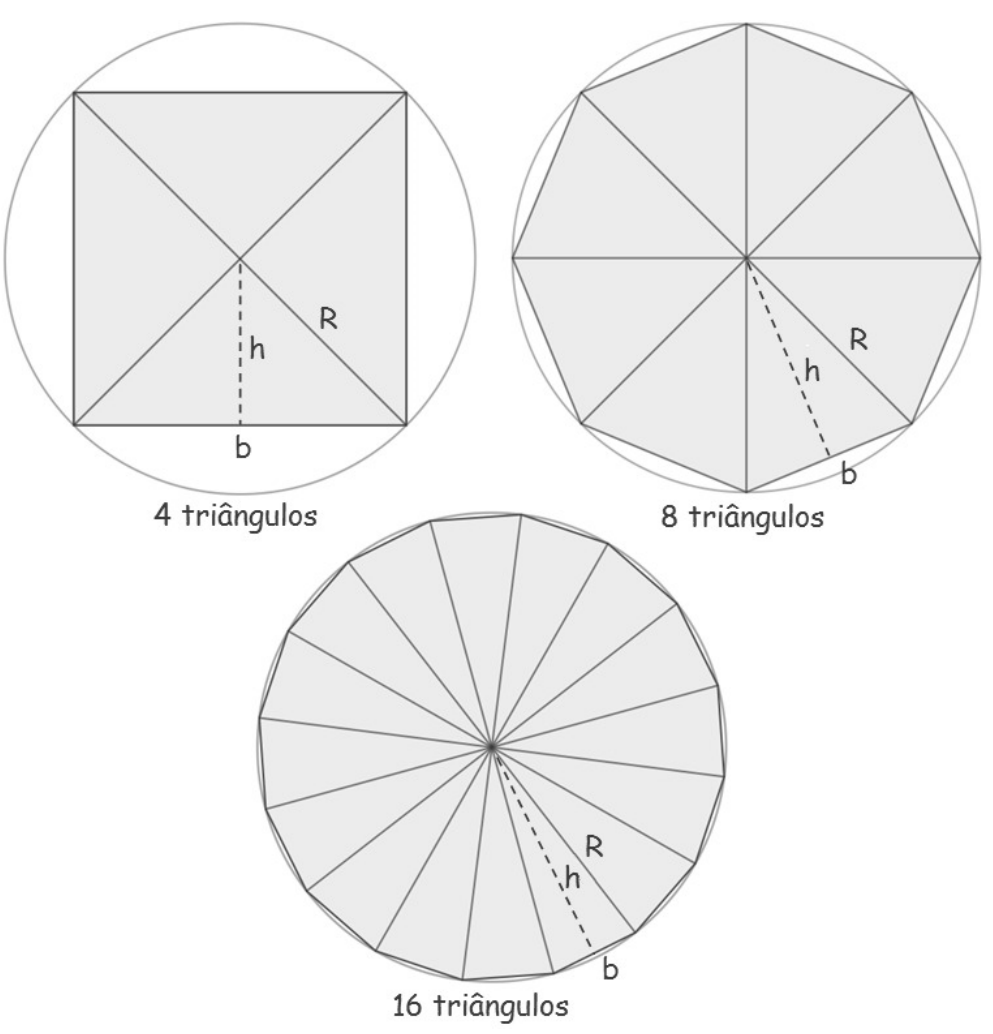

Figura 2: Tentando preencher um círculo com triângulos. Quando o número de triângulos usados tende a infinito, a área total dos triângulos tende à área do círculo.

O que vimos neste tópico está intimamente relacionado ao conceito de integral definida, que começaremos a estudar na seção "A integral definida".

\section{Reta tangente como o limite de uma sequência de retas secantes}

A Fig. 3 exibe o gráfico de uma certa função $f(x)$, e também um conjunto de retas secantes a esse gráfico, além de uma reta tangente ao gráfico no ponto $P$. Considere que as retas secantes $s_{1}, s_{2}$ e $s_{3}$ foram construídas da seguinte forma: a reta $s_{1}$ intercepta o gráfico nos pontos $P$ e $Q_{1}$; a reta $s_{2}$ intercepta o gráfico nos pontos $P$ e $Q_{2}$, estando o ponto $Q_{2}$ mais próximo do ponto $P$ (sendo, porém, distinto deste) que do ponto $Q_{1}$ (com distâncias medidas ao longo do gráfico); a reta $s_{3}$ intercepta o gráfico nos pontos $P$ e $Q_{3}$, estando o ponto $Q_{3}$ mais próximo do ponto $P$ que do ponto $Q_{2}$. Podemos continuar essa sequência de retas secantes, obtendo retas $s_{4}, s_{5}, s_{6}, \ldots$ Quanto mais avançarmos nesta sequência, mais nos aproximaremos da reta tangente $t$, sem, contudo, jamais atingi-la, concorda? Podemos afirmar que a reta tangente $t$ é o limite de uma sequência de retas secantes $s_{1}, s_{2}, s_{3}, \ldots$ construída segundo a regra apresentada acima - a saber: a reta $s_{i}$ intercepta o gráfico nos pontos $P$ e $Q_{i}$, estando o ponto $Q_{i}$ mais próximo do ponto $P$ que do ponto $Q_{i-1}$.

Nosso desejo é que você se familiarize com o conceito de limite em diferentes contextos. O que vimos neste tópico está relacionado ao conceito de derivada - ou melhor, a uma interpretação geométrica da derivada de uma função $f(x)$. Veremos isso mais adiante. 


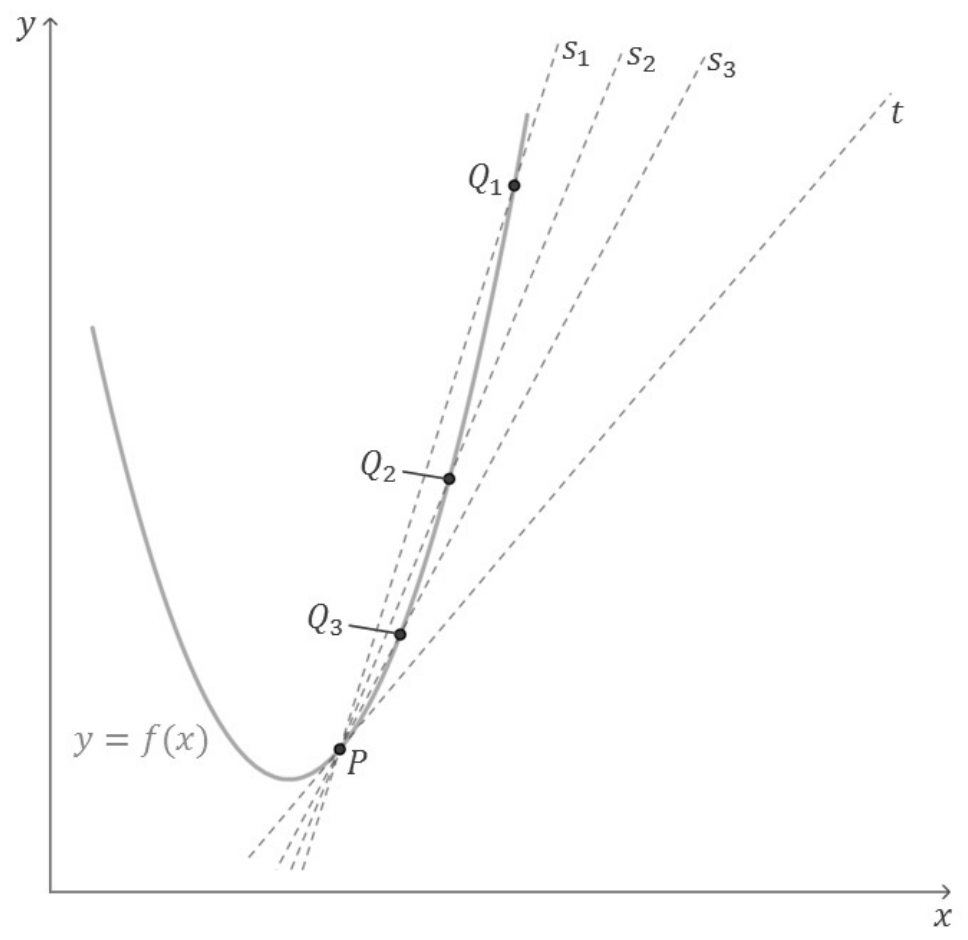

Figura 3: Reta tangente, $t$, como o limite de uma sequência de retas secantes $s_{1}, s_{2}, s_{3}, \ldots$

\section{A derivada}

\section{A derivada de uma função}

Na seção "Limites de funções - uma introdução" dissemos que o tipo de limite que encontramos na definição da velocidade instantânea de uma partícula (veja a igualdade (1)) tem um nome especial: derivada.

A derivada de uma função $f(x)$, denotada por $f^{\prime}(x)$, é definida como

$$
f^{\prime}(x)=\lim _{\Delta x \rightarrow 0} \frac{f(x+\Delta x)-f(x)}{\Delta x}
$$

quando este limite existe.

Exemplo: Seja $f(x)=x^{2}$. Temos:

$$
\begin{aligned}
f^{\prime}(x) & =\lim _{\Delta x \rightarrow 0} \frac{f(x+\Delta x)-f(x)}{\Delta x}=\lim _{\Delta x \rightarrow 0} \frac{(x+\Delta x)^{2}-x^{2}}{\Delta x}=\lim _{\Delta x \rightarrow 0} \frac{\chi^{2}+2 x \Delta x+(\Delta x)^{2}-\chi^{2}}{\Delta x} \\
& =\lim _{\Delta x \rightarrow 0}(2 x+\Delta x)=2 x .
\end{aligned}
$$

Logo, a derivada de $f(x)=x^{2}$ é $f^{\prime}(x)=2 x$.

É claro que temos em (1) e (2) o mesmo tipo de limite. A diferença é que em (1) temos a função $s(t)$ e em (2) temos a função $f(x)$, esta última representando uma função genérica. Troque, no limite expresso em (1), $t$ por $x$ e $s$ por $f$, e você obterá o limite expresso em (2).

É comum encontrar, na definição de derivada de uma função $f(x)$, “ $h$ " em vez de " $\Delta x$ ":

$$
f^{\prime}(x)=\lim _{h \rightarrow 0} \frac{f(x+h)-f(x)}{h} .
$$


Não faz diferença, já que ao final do cálculo do limite não teremos nem $\Delta x$ nem $h$. Sugerimos que você refaça as contas do exemplo acima usando $h$, em vez de $\Delta x$, e, em seguida, resolva o Exercício 5 da lista.

\section{A derivada como uma taxa de variação}

Sejam $y$ e $x$ duas variáveis relacionadas através de uma certa função $f: y=f(x)$. Podemos escrever, simplesmente, $y=y(x)$. A derivada de $y$ em relação a $x$,

$$
y^{\prime}(x)=\lim _{\Delta x \rightarrow 0} \frac{\Delta y}{\Delta x}=\lim _{\Delta x \rightarrow 0} \frac{y(x+\Delta x)-y(x)}{\Delta x},
$$

é uma medida de quão rápido $y$ muda quando $x$ muda, e damos a essa medida o nome taxa de variação de $y$ em relação a $x$.

Exemplo: Vamos calcular a taxa de variação da área $A$ de um círculo em relação a seu raio $r$ (lembre-se que $A(r)=\pi r^{2}$ ).

$$
\begin{aligned}
A^{\prime}(r) & =\lim _{\Delta r \rightarrow 0} \frac{\Delta A}{\Delta r}=\lim _{\Delta r \rightarrow 0} \frac{A(r+\Delta r)-A(r)}{\Delta r}=\lim _{\Delta r \rightarrow 0} \frac{\pi(r+\Delta r)^{2}-\pi r^{2}}{\Delta r} \\
& =\pi \lim _{\Delta r \rightarrow 0} \frac{\not^{2}+2 r \Delta r+(\Delta r)^{2}-\not^{\not 2}}{\Delta r}=\pi \lim _{\Delta r \rightarrow 0}(2 r+\Delta r)=2 \pi r .
\end{aligned}
$$

Logo, a taxa de variação de $A$ em relação a $r$ é $A^{\prime}(r)=2 \pi r$. Observe que à medida que o raio $r$ muda (aumentando ou diminuindo), a área $A$ muda tão mais rapidamente quanto maior for o valor de $r$. Assim, se $r$ estiver aumentando uniformemente, $A$ irá aumentar cada vez mais rapidamente. Se $r$ estiver diminuindo uniformemente, $A$ irá diminuir cada vez mais lentamente. Procure enxergar isso. E procure enxergar também (não se contente em simplesmente aceitar) que os limites em (3) constituem uma medida de quão rápido $y$ muda à medida que $x$ muda.

A velocidade instantânea (veja a igualdade (1)) é uma taxa de variação da posição $s$ em relação ao tempo $t$. Boa parte das taxas de variação são taxas de variação de uma grandeza em relação ao tempo. Mas nem sempre é assim. Por exemplo, vimos que podemos calcular a taxa de variação da área de um círculo em relação ao seu raio. É claro, podemos ter em mente uma variação desse raio com o tempo (como no caso da dilatação térmica de um disco metálico), mas não necessariamente.

Sugerimos que você resolva agora o Exercício 6.

\section{Regras básicas para o cálculo de derivadas}

Calcular a derivada $f^{\prime}(x)$ de uma função $f(x)$ diretamente a partir da igualdade (2), que a define, é impraticável para a maioria das funções. Na prática, fazemos uso de uma série de regras básicas para o cálculo de derivadas. Veremos algumas dessas regras nesta seção; outras, estudaremos mais adiante.

\section{Regra da constante}

$$
f(x)=c \Longrightarrow f^{\prime}(x)=0(c \text { constante })
$$

Demonstração:

$$
f^{\prime}(x)=\lim _{\Delta x \rightarrow 0} \frac{f(x+\Delta x)-f(x)}{\Delta x}=\lim _{\Delta x \rightarrow 0} \frac{c-c}{\Delta x}=\lim _{\Delta x \rightarrow 0} 0=0 .
$$




\section{Um curso rápido de cálculo diferencial e integral para pré-universitários e calouros}

Trata-se de um resultado esperado. Pensando a derivada como uma taxa de variação: a taxa de variação de uma constante é, obviamente, nula.

\section{Regra da potência com expoente $n=1,2$ ou 3}

$$
f(x)=x^{n} \Longrightarrow f^{\prime}(x)=n x^{n-1}(n=1,2 \text { ou } 3) .
$$

Demonstração:

Deixaremos parte da demonstração como exercício para você. Partindo da igualdade (2) mostre, separadamente, que

$$
\begin{aligned}
& f(x)=x \Longrightarrow f^{\prime}(x)=1 ; \\
& f(x)=x^{2} \Longrightarrow f^{\prime}(x)=2 x ; \\
& f(x)=x^{3} \Longrightarrow f^{\prime}(x)=3 x^{2} .
\end{aligned}
$$

Neste último caso, use a identidade $(x+\Delta x)^{3}=x^{3}+3 x^{2} \Delta x+3 x(\Delta x)^{2}+(\Delta x)^{3}$. Com um pouco de atenção, podemos reunir os resultados dos casos $n=1, n=2$ e $n=3$ em uma única fórmula: $f(x)=x^{n} \Longrightarrow f^{\prime}(x)=n x^{n-1}(n=1,2$ ou 3$)$, o que conclui a demonstração.

\section{Regra da homogeneidade}

$$
f(x)=c g(x) \Longrightarrow f^{\prime}(x)=c g^{\prime}(x)(c \text { constante }) .
$$

\section{Demonstração:}

$f^{\prime}(x)=\lim _{\Delta x \rightarrow 0} \frac{f(x+\Delta x)-f(x)}{\Delta x}=\lim _{\Delta x \rightarrow 0} \frac{c g(x+\Delta x)-c g(x)}{\Delta x}=c \lim _{\Delta x \rightarrow 0} \frac{g(x+\Delta x)-g(x)}{\Delta x}=c g^{\prime}(x)$.

Você deve ter notado que usamos, nesta demonstração, uma propriedade de limites: a Propriedade 2 apresentada na seção "Propriedades básicas de limites". (Também fizemos uso dessa propriedade no exemplo da seção "A derivada como uma taxa de variação", quando movemos $\pi$ através do símbolo de limite.)

É interessante observar que frequentemente usamos as duas últimas regras conjuntamente. Por exemplo, se $f(x)=4 x^{3}$, então $f^{\prime}(x)=\left[4 x^{3}\right]^{\prime}=4\left[x^{3}\right]^{\prime}=4 \cdot 3 x^{2}=12 x^{2}$. Na prática, fazemos esse cálculo de forma mais direta: multiplicamos o expoente 3 pelo coeficiente 4 e, em seguida, subtraímos uma unidade do expoente. Ou seja, escrevemos, de forma direta: $f(x)=4 x^{3} \Longrightarrow f^{\prime}(x)=12 x^{2}$.

\section{Regra da soma}

$$
f(x)=g(x)+h(x) \Longrightarrow f^{\prime}(x)=g^{\prime}(x)+h^{\prime}(x) .
$$

Demonstração:

$$
\begin{aligned}
f^{\prime}(x) & =\lim _{\Delta x \rightarrow 0} \frac{f(x+\Delta x)-f(x)}{\Delta x}=\lim _{\Delta x \rightarrow 0} \frac{[g(x+\Delta x)+h(x+\Delta x)]-[g(x)+h(x)]}{\Delta x} \\
& =\lim _{\Delta x \rightarrow 0}\left[\frac{g(x+\Delta x)-g(x)}{\Delta x}+\frac{h(x+\Delta x)-h(x)}{\Delta x}\right] \\
& =\lim _{\Delta x \rightarrow 0} \frac{g(x+\Delta x)-g(x)}{\Delta x}+\lim _{\Delta x \rightarrow 0} \frac{h(x+\Delta x)-h(x)}{\Delta x}=g^{\prime}(x)+h^{\prime}(x) .
\end{aligned}
$$




\section{Um curso rápido de cálculo diferencial e integral para pré-universitários e calouros}

Perceba como a manipulação algébrica foi fundamental, nesta demonstração. E você deve ter notado que usamos uma propriedade de limites: a Propriedade 1 apresentada na seção "Propriedades básicas de limites".

\section{Regra da diferença}

$$
f(x)=g(x)-h(x) \Longrightarrow f^{\prime}(x)=g^{\prime}(x)-h^{\prime}(x) .
$$

Demonstração:

Ficará como um exercício para você demonstrar a regra da diferença de forma similar à demonstração apresentada para a regra da soma. Aqui, demonstraremos a regra da diferença de outra forma: fazendo uso da regra da soma e da regra da homogeneidade.

$$
\begin{aligned}
f^{\prime}(x) & =[g(x)-h(x)]^{\prime}=[g(x)+(-1 \cdot h(x))]^{\prime}=g^{\prime}(x)+(-1 \cdot h(x))^{\prime}=g^{\prime}(x)+\left(-1 \cdot h^{\prime}(x)\right) \\
& =g^{\prime}(x)-h^{\prime}(x) .
\end{aligned}
$$

Temos aqui um exemplo de um tipo de procedimento bastante comum e bastante importante em matemática: a obtenção de um determinado resultado fazendo-se uso de resultados anteriores. Lembre-se: nem sempre é necessário, nem desejável, partir do início.

\section{Extensão da regra da soma de duas para $\mathbf{n}$ funções}

$$
f(x)=f_{1}(x)+f_{2}(x)+\cdots+f_{n}(x) \Longrightarrow f^{\prime}(x)=f_{1}^{\prime}(x)+f_{2}^{\prime}(x)+\cdots+f_{n}^{\prime}(x) .
$$

\section{Demonstração:}

A estratégia é fazermos uso da regra da soma para duas funções, já demonstrada, tantas vezes quantas forem necessárias. Vejamos:

$$
\begin{aligned}
f^{\prime}(x) & =\left[f_{1}(x)+f_{2}(x)+\cdots+f_{n}(x)\right]^{\prime}=\left\{f_{1}(x)+\left[f_{2}(x)+\cdots+f_{n}(x)\right]\right\}^{\prime} \\
& =f_{1}^{\prime}(x)+\left[f_{2}(x)+\cdots+f_{n}(x)\right]^{\prime}=f_{1}^{\prime}(x)+\left\{f_{2}(x)+\left[f_{3}(x)+\cdots+f_{n}(x)\right]\right\}^{\prime} \\
& =f_{1}^{\prime}(x)+f_{2}^{\prime}(x)+\left[f_{3}(x)+\cdots+f_{n}(x)\right]^{\prime} .
\end{aligned}
$$

Continuando, obtemos

$$
f^{\prime}(x)=f_{1}^{\prime}(x)+f_{2}^{\prime}(x)+\cdots+f_{n}^{\prime}(x) .
$$

Com o que temos até aqui, podemos facilmente calcular a derivada de uma função como $f(x)=5 x^{3}-2 x^{2}+x$. Fazendo passo a passo, temos:

$$
\begin{aligned}
{\left[5 x^{3}-2 x^{2}+x\right]^{\prime} } & =\left[5 x^{3}+\left(-2 x^{2}\right)+x\right]^{\prime}=\left[5 x^{3}\right]^{\prime}+\left[-2 x^{2}\right]^{\prime}+[x]^{\prime}=5\left[x^{3}\right]^{\prime}+(-2)\left[x^{2}\right]^{\prime}+1 \\
& =5 \cdot 3 x^{2}-2 \cdot 2 x+1=15 x^{2}-4 x+1
\end{aligned}
$$

Na prática, escrevemos, de forma direta:

$$
\left[5 x^{3}-2 x^{2}+x\right]^{\prime}=15 x^{2}-4 x+1
$$




\section{Um curso rápido de cálculo diferencial e integral para pré-universitários e calouros}

\section{Regra do produto}

$$
f(x)=g(x) h(x) \Longrightarrow f^{\prime}(x)=g^{\prime}(x) h(x)+g(x) h^{\prime}(x) .
$$

Demonstração:

A demonstração apresentada a seguir envolve manipulações algébricas que exigem mais criatividade que nas demonstrações anteriores. Vejamos:

$$
f^{\prime}(x)=\lim _{\Delta x \rightarrow 0} \frac{f(x+\Delta x)-f(x)}{\Delta x}=\lim _{\Delta x \rightarrow 0} \frac{g(x+\Delta x) h(x+\Delta x)-g(x) h(x)}{\Delta x} .
$$

Podemos reescrever o numerador desta última fração como

$$
g(x+\Delta x) h(x+\Delta x)-g(x) h(x+\Delta x)+g(x) h(x+\Delta x)-g(x) h(x) .
$$

Verifique que, com isso, obtemos:

$$
\begin{aligned}
f^{\prime}(x) & =\lim _{\Delta x \rightarrow 0}\left[\frac{g(x+\Delta x)-g(x)}{\Delta x} h(x+\Delta x)\right]+\lim _{\Delta x \rightarrow 0}\left[g(x) \frac{h(x+\Delta x)-h(x)}{\Delta x}\right] \\
& =g^{\prime}(x) h(x)+g(x) h^{\prime}(x) .
\end{aligned}
$$

\section{Regra do quociente}

Demonstração:

$$
f(x)=\frac{g(x)}{h(x)} \Longrightarrow f^{\prime}(x)=\frac{g^{\prime}(x) h(x)-g(x) h^{\prime}(x)}{[h(x)]^{2}}
$$

$$
\begin{aligned}
f^{\prime}(x) & =\lim _{\Delta x \rightarrow 0} \frac{f(x+\Delta x)-f(x)}{\Delta x}=\lim _{\Delta x \rightarrow 0} \frac{\frac{g(x+\Delta x)}{h(x+\Delta x)}-\frac{g(x)}{h(x)}}{\Delta x} \\
& =\lim _{\Delta x \rightarrow 0}\left[\frac{1}{\Delta x} \frac{g(x+\Delta x) h(x)-g(x) h(x+\Delta x)}{h(x+\Delta x) h(x)}\right] \\
& =\frac{1}{[h(x)]^{2}} \lim _{\Delta x \rightarrow 0}\left[\frac{g(x+\Delta x) h(x)-g(x) h(x+\Delta x)}{\Delta x}\right] .
\end{aligned}
$$

Podemos reescrever o numerador desta última fração como

$$
g(x+\Delta x) h(x)-g(x) h(x)+g(x) h(x)-g(x) h(x+\Delta x) .
$$

Verifique que com isso obtemos:

$$
\begin{aligned}
f^{\prime}(x) & =\frac{1}{[h(x)]^{2}}\left\{\lim _{\Delta x \rightarrow 0}\left[\frac{g(x+\Delta x)-g(x)}{\Delta x} h(x)\right]+\lim _{\Delta x \rightarrow 0}\left[-g(x) \frac{h(x+\Delta x)-h(x)}{\Delta x}\right]\right\} \\
& =\frac{g^{\prime}(x) h(x)-g(x) h^{\prime}(x)}{[h(x)]^{2}} .
\end{aligned}
$$

Como exemplo, vamos calcular a derivada de $f(x)=\left(x^{2}-4\right) /(x-2)($ para $x \neq 2)$ usando a regra do quociente.

$$
f^{\prime}(x)=\frac{2 x(x-2)-\overbrace{\left(x^{2}-4\right)}^{(x-2)(x+2)} \cdot 1}{(x-2)^{2}}=\frac{x-2}{x-2}=1 .
$$




\section{Um curso rápido de cálculo diferencial e integral para pré-universitários e calouros}

Perceba que poderíamos ter calculado a derivada acima de forma mais direta (mas nem sempre dá pra fazer isso, é claro):

$$
f(x)=\frac{x^{2}-4}{x-2}=\frac{(x-2)(x+2)}{x-2}=x+2 \Longrightarrow f^{\prime}(x)=1 .
$$

Fica aqui uma dica: é quase sempre vantajoso simplificar a expressão que define a função (quando há o que simplificar) antes de calcular sua derivada.

\section{Regra da potência com expoente natural $\mathbf{n} \neq \mathbf{0}$}

$$
f(x)=x^{n} \Longrightarrow f^{\prime}(x)=n x^{n-1}(n=1,2,3, \ldots) .
$$

\section{Demonstração:}

Já demonstramos essa regra para $n=1,2$ ou 3. Agora, vamos mostrar que ela é válida para qualquer número natural $n \neq 0$. A estratégia é a seguinte: vamos mostrar que se essa regra é válida para um certo número natural $n \neq 0$, então ela é válida para $n+1$. (Você percebe por que isso é suficiente?) Ou seja, vamos mostrar que se $\left[x^{n}\right]^{\prime}=n x^{n-1}$, então $\left[x^{n+1}\right]^{\prime}=(n+1) x^{n+1-1}$. Para isso, faremos uso da regra do produto. Vejamos:

$$
\left[x^{n+1}\right]^{\prime}=\left[x^{n} x\right]^{\prime}=\left[x^{n}\right]^{\prime} x+x^{n}[x]^{\prime}=n x^{n-1} x+x^{n}=n x^{n}+x^{n}=(n+1) x^{n}=(n+1) x^{n+1-1} .
$$

\section{Regra da potência com expoente inteiro $\mathbf{n} \neq \mathbf{0}$}

$$
f(x)=x^{n} \Longrightarrow f^{\prime}(x)=n x^{n-1}\left(n \in \mathbb{Z}^{*}\right) .
$$

Demonstração:

Acabamos de demonstrar que essa regra é válida para todo $n$ inteiro positivo. Assim, só precisaremos mostrar que ela também é válida para todo $n$ inteiro negativo. Para $n$ inteiro negativo, temos $n=-|n|$, e, portanto:

$$
\left[x^{n}\right]^{\prime}=\left[x^{-|n|}\right]^{\prime}=\left[\frac{1}{x^{|n|}}\right]^{\prime}=\frac{\overbrace{[1]^{\prime}}^{0} x^{|n|}-1 \cdot\left[x^{|n|}\right]^{\prime}}{\left(x^{|n|}\right)^{2}}=\frac{-|n| x^{|n|-1}}{x^{2|n|}}=-|n| x^{-|n|-1}=n x^{n-1} .
$$

Um exemplo: $\left[x^{-5}\right]^{\prime}=-5 x^{-6}$.

\section{Resumo das regras básicas para o cálculo de derivadas}

Vamos reunir aqui as regras básicas para o cálculo de derivadas que estudamos nesta seção. Escolhemos " $u$ " e " $v$ " para denotar funções de $x$ porque trata-se de uma escolha muito comum em livros de cálculo, e é interessante você se familiarizar com ela. Quando usada, $c$ 


\section{Um curso rápido de cálculo diferencial e integral para pré-universitários e calouros}

denota uma constante 3

$$
\begin{array}{lr}
{[c]^{\prime}=0} & \text { (regra da constante) } \\
{\left[x^{n}\right]^{\prime}=n x^{n-1}\left(n \in \mathbb{Z}^{*}\right)} & \text { (regra da potência) } \\
{[c u]^{\prime}=c u^{\prime}} & \text { (regra da homogeneidade) } \\
{[u+v]^{\prime}=u^{\prime}+v^{\prime}} & \text { (regra da soma) } \\
{[u-v]^{\prime}=u^{\prime}-v^{\prime}} & \text { (regra da diferença) } \\
{[u v]^{\prime}=u^{\prime} v+u v^{\prime}} & \text { (regra do produto) } \\
{\left[\frac{u}{v}\right]^{\prime}=\frac{u^{\prime} v-u v^{\prime}}{v^{2}}} & \text { (regra do quociente) }
\end{array}
$$

Lembrando que mostramos que a regra da soma pode ser estendida para um número finito qualquer de funções.

Sugerimos que você resolva agora os Exercícios 7 a 11 .

\section{Notação de Leibniz}

Até aqui, denotamos a derivada de uma função $f(x)$ por $f^{\prime}(x)$ ou $[f(x)]^{\prime}$. Há outras notações, como $f_{x}(x)$ e $\mathrm{D}_{x} f(x)$, menos usadas no cálculo com funções reais de uma variável real. Mas há uma notação que é a preferida de praticamente todos os físicos e engenheiros: a chamada notação de Leibniz.

Seja $y=y(x)$. Temos

$$
y^{\prime}(x)=\lim _{\Delta x \rightarrow 0} \frac{y(x+\Delta x)-y(x)}{\Delta x}=\lim _{\Delta x \rightarrow 0} \frac{\Delta y}{\Delta x} .
$$

Podemos pensar o limite acima como a razão entre duas quantidades "infinitamente pequenas", que chamaremos de quantidades infinitesimais: $\mathrm{d} y$ e $\mathrm{d} x$. Assim, escrevemos:.$^{4}$

$$
y^{\prime}(x)=\lim _{\Delta x \rightarrow 0} \frac{\Delta y}{\Delta x}=\frac{\mathrm{d} y}{\mathrm{~d} x} .
$$

Pense $\mathrm{d} x$ como um $\Delta x$ muito, muito, muito pequeno, e $\mathrm{d} y$ como o $\Delta y$ correspondente (em geral também muito, muito, muito pequeno, mas podendo ser nulo). Do ponto de vista técnico, temos o problema da falta de rigor no conceito de uma quantidade infinitamente pequena. Os matemáticos resolvem isso definindo $\mathrm{d} x$ como um número real não nulo qualquer e $\mathrm{d} y$ como $y^{\prime}(x) \mathrm{d} x$, e com isso temos, é claro, $\mathrm{d} y / \mathrm{d} x=y^{\prime}(x)$. Mas acredite: não é isso o que físicos e engenheiros costumam ter em mente quando trabalham com a notação de Leibniz, $\mathrm{d} y / \mathrm{d} x$, para a derivada de $y(x)$. Eles imaginam a razão entre uma variação infinitesimal de $y$ e uma variação infinitesimal de $x$ (lembrando que dy e d $x$ não são independentes, pois $y=y(x)$ ), embora saibam que, tecnicamente, estão tomando o limite da razão $\Delta y / \Delta x$, quando $\Delta x \rightarrow 0$. Variações infinitesimais como dy e $\mathrm{d} x$ são denominadas diferenciais.

Vejamos um exemplo na física. Considere uma partícula cuja posição $s$ varia com o tempo $t$ de acordo com a função $s(t)=5 t^{3}$ (com $s$ em metros e $t$ em segundos). Qual é a

\footnotetext{
${ }^{3}$ Demonstraremos na seção "Regra da cadeia" que a regra da potência também é válida para expoentes racionais não inteiros, como $3 / 2$.

4 " $\Delta$ " é a quarta letra do alfabeto grego, e "d" é a quarta letra de nosso alfabeto, sendo que $\Delta$ é uma letra maiúscula; sua versão minúscula é $\delta$.
} 


\section{Um curso rápido de cálculo diferencial e integral para pré-universitários e calouros}

velocidade dessa partícula, em função do tempo? Usando a notação de Leibniz (aplicando regras básicas para o cálculo de derivadas), escrevemos:

$$
v(t)=\frac{\mathrm{d} s}{\mathrm{~d} t}=15 t^{2}(\text { no SI })
$$

E quando escrevemos $v=\mathrm{d} s / \mathrm{d} t$, estamos pensando a velocidade $v$ como a razão entre um deslocamento infinitesimal $\mathrm{d} s$ e o intervalo de tempo infinitesimal correspondente $\mathrm{d} t$. Muito intuitivo, e, como veremos, muito útil.

Mais um exemplo:

$$
s(t)=s_{0}+v_{0} t+\frac{1}{2} a t^{2}\left(s_{0}, v_{0} \text { e } a \text { constantes }\right) \Longrightarrow v(t)=\frac{\mathrm{d} s}{\mathrm{~d} t}=v_{0}+a t .
$$

Ainda sobre notação,

$$
\left.\frac{\mathrm{d} y}{\mathrm{~d} x}\right|_{x=a} \text { significa } y^{\prime}(a)
$$

e $\frac{d}{d x}$ significa “derive, em relação a $x$, a função à direita", de modo que, por exemplo,

$$
\frac{\mathrm{d}}{\mathrm{d} x}\left(5 x^{4}-x\right)=20 x^{3}-1
$$

\section{Regra da cadeia}

A regra da cadeia é uma regra importantíssima para o cálculo de derivadas. Sem ela, não vamos muito longe.

Exemplo: Qual é a derivada de $f(x)=\left(5 x^{3}+2 x\right)^{100}$ ? As regras básicas que temos não se aplicam (de forma prática) a esta função. E partir da definição em (2) não é uma opção interessante. Talvez alguém pense em usar a regra da potência, escrevendo: $f^{\prime}(x)=100\left(5 x^{3}+2 x\right)^{99}$. Porém, provamos que a regra da potência vale para uma potência de base $x$ e expoente inteiro não-nulo, mas aqui a base não é $x$, e sim $5 x^{3}+2 x$. Felizmente, existe um artifício extremamente engenhoso para o cálculo da derivada de uma função como $f(x)=\left(5 x^{3}+2 x\right)^{100}$. Seja $u=5 x^{3}+2 x$. Usando " $y$ " no lugar de " $f(x)$ ", temos: $y=\left(5 x^{3}+2 x\right)^{100}=u^{100}$. Segue que

$$
f^{\prime}(x)=\frac{\mathrm{d} y}{\mathrm{~d} x}=\frac{\mathrm{d} y}{\mathrm{~d} u} \frac{\mathrm{d} u}{\mathrm{~d} x} .
$$

Mas

$\mathrm{e}$

$$
\frac{\mathrm{d} y}{\mathrm{~d} u}=100 u^{99}=100\left(5 x^{3}+2 x\right)^{99}
$$

$$
\frac{\mathrm{d} u}{\mathrm{~d} x}=15 x^{2}+2
$$

Assim,

$$
f^{\prime}(x)=\frac{\mathrm{d} y}{\mathrm{~d} x}=\frac{\mathrm{d} y}{\mathrm{~d} u} \frac{\mathrm{d} u}{\mathrm{~d} x}=100\left(5 x^{3}+2 x\right)^{99}\left(15 x^{2}+2\right) .
$$

A partir deste exemplo, vamos apresentar a regra da cadeia:

Seja $y$ uma função de $u$, e $u$ uma função de $x$. A derivada de $y$ em relação a $x$ $(\mathrm{d} y / \mathrm{d} x)$ é igual à derivada de $y$ em relação a $u(\mathrm{~d} y / \mathrm{d} u)$ vezes a derivada de $u$ em relação a $x(\mathrm{~d} u / \mathrm{d} x)$. 
Chegamos à regra da cadeia fazendo em (4) uma manipulação algébrica trivial. Mas a demonstração matemática rigorosa da regra da cadeia é muito mais complicada que isso, porque em tal demonstração não trabalhamos com a derivada como a razão entre duas quantidades infinitesimais.

Sugerimos que você resolva agora o Exercício 12.

\section{Regra da potência com expoente racional $\mathbf{r} \neq \mathbf{0}$}

Procure compreender a regra da cadeia sem se prender à sequência $y=y(u)$ e $u=u(x)$, apresentada acima. Podemos mudar as letras usadas. Por exemplo, sejam $u=u(y)$ e $y=y(x)$. A regra da cadeia nos diz que a derivada de $u$ em relação a $x(\mathrm{~d} u / \mathrm{d} x)$ é igual à derivada de $u$ em relação a $y(\mathrm{~d} u / \mathrm{d} y)$ vezes a derivada de $y$ em relação a $x(\mathrm{~d} y / \mathrm{d} x)$ :

$$
\frac{\mathrm{d} u}{\mathrm{~d} x}=\frac{\mathrm{d} u}{\mathrm{~d} y} \frac{\mathrm{d} y}{\mathrm{~d} x} .
$$

Faremos uso desta sequência logo abaixo, para mostrar que a regra da potência também é válida para expoentes racionais não inteiros; ou seja,

$$
f(x)=x^{r} \Longrightarrow f^{\prime}(x)=r x^{r-1}\left(r \in \mathbb{Q}^{*}\right) .
$$

Demonstração:

Seja $r=m / n$, sendo $m$ e $n$ dois inteiros não nulos quaisquer, e seja $y=x^{r}$. Temos

$$
y=x^{r}=x^{m / n} \Longrightarrow y^{n}=x^{m} \text {. }
$$

Derivando em relação a $x$ ambos os membros da última igualdade, obtemos (lembrando que $y$ é uma função de $x$, e aplicando a regra da cadeia):

$$
\underbrace{\frac{\mathrm{d}}{\mathrm{d} x} \overbrace{y^{n}}^{u}}_{\frac{\mathrm{d} u \mathrm{~d} y}{\mathrm{~d} y} \mathrm{~d} x}=\frac{\mathrm{d}}{\mathrm{d} x} x^{m} \Longrightarrow n y^{n-1} \frac{\mathrm{d} y}{\mathrm{~d} x}=m x^{m-1} .
$$

Vamos resolver esta equação para $\mathrm{d} y / \mathrm{d} x$ :

$$
\frac{\mathrm{d} y}{\mathrm{~d} x}=\frac{m}{n} \frac{x^{m-1}}{y^{n-1}}=\frac{m}{n} \frac{x^{m-1}}{\left(x^{m / n}\right)^{n-1}}=\frac{m}{n} x^{\frac{m}{n}-1}=r x^{r-1},
$$

o que conclui a demonstração.

Exemplo: $[\sqrt{x}]^{\prime}=\left[x^{1 / 2}\right]^{\prime}=\frac{1}{2} x^{\frac{1}{2}-1}=\frac{1}{2} x^{-\frac{1}{2}}=\frac{1}{2 \sqrt{x}}$.

\section{Derivadas de ordem superior}

A derivada $f^{\prime}(x)$ de uma função $f(x)$ também é uma função; em princípio, podemos derivá-la. Denotamos a derivada de $f^{\prime}(x)$ por $f^{\prime \prime}(x)$, e a chamamos de derivada segunda de $f(x)$ ou segunda derivada de $f(x)$, ou, ainda, derivada de segunda ordem de $f(x)$.

É claro, em princípio também podemos derivar a função $f^{\prime \prime}(x)$. Assim, continuando o processo de derivação vamos obtendo as funções $f^{\prime \prime \prime}(x), f^{(4)}(x), f^{(5)}(x), \ldots$

Exemplo: Vamos calcular a derivada de terceira ordem da função $f(x)=4 x^{6}-2 x$. Temos $f^{\prime}(x)=24 x^{5}-2, f^{\prime \prime}(x)=120 x^{4}$ e, então, $f^{\prime \prime \prime}(x)=480 x^{3}$. 


\section{Um curso rápido de cálculo diferencial e integral para pré-universitários e calouros}

Na notação de Leibniz, derivadas de ordem superior são expressas como

$$
\frac{\mathrm{d}^{2} y}{\mathrm{~d} x^{2}}, \frac{\mathrm{d}^{3} y}{\mathrm{~d} x^{3}}, \frac{\mathrm{d}^{4} y}{\mathrm{~d} x^{4}}, \ldots, \frac{\mathrm{d}^{n} y}{\mathrm{~d} x^{n}}, \ldots
$$

Trata-se apenas de uma notação. O " 2 ” em d $\mathrm{d}^{2} y / \mathrm{d} x^{2}$ não é, obviamente, um expoente. E lemos: "d dois $y, \mathrm{~d} x$ dois".

Vejamos um exemplo na física. A aceleração instantânea de uma partícula é a taxa de variação de sua velocidade em relação ao tempo. Assim, escrevemos:

$$
a=\frac{\mathrm{d} v}{\mathrm{~d} t} .
$$

Mas como $v=\mathrm{d} s / \mathrm{d} t$, segue que

$$
a=\frac{\mathrm{d} v}{\mathrm{~d} t}=\frac{\mathrm{d}}{\mathrm{d} t}\left(\frac{\mathrm{d} s}{\mathrm{~d} t}\right)=\frac{\mathrm{d}^{2} s}{\mathrm{~d} t^{2}} .
$$

Portanto, a aceleração instantânea (ou, simplesmente, aceleração) é a derivada segunda da posição em relação ao tempo.

Sugerimos que você resolva agora os Exercícios 13 a 15.

\section{A derivada como o coeficiente angular da reta tangente}

Você sabe que o gráfico de uma função $f(x)=a x+b$ (com $a$ e $b$ constantes, $a \neq 0$ ), denominada função afim, é uma reta. E qualquer reta não paralela ao eixo y é o gráfico de uma função afim. O coeficiente $b$ é denominado coeficiente linear, e é onde o gráfico de $f(x)$ intercepta o eixo $y$ (veja a Fig.4). O coeficiente $a$ é denominado coeficiente angular, e nos dá a inclinação da reta. Considerando o triângulo retângulo da Fig.4, você pode facilmente mostrar que $a=\operatorname{tg} \theta$, em que $\theta$ é o ângulo que a reta faz com o eixo $x$. Se $a<0$, temos $\theta<0-$ o que significa que a reta tem "inclinação negativa" (quando $x$ aumenta, $y$ diminui).

Pois bem, temos $f^{\prime}(x)=[a x+b]^{\prime}=a=\operatorname{tg} \theta$. Ou seja, a derivada de uma função afim $f(x)=a x+b$ é igual ao seu coeficiente angular.

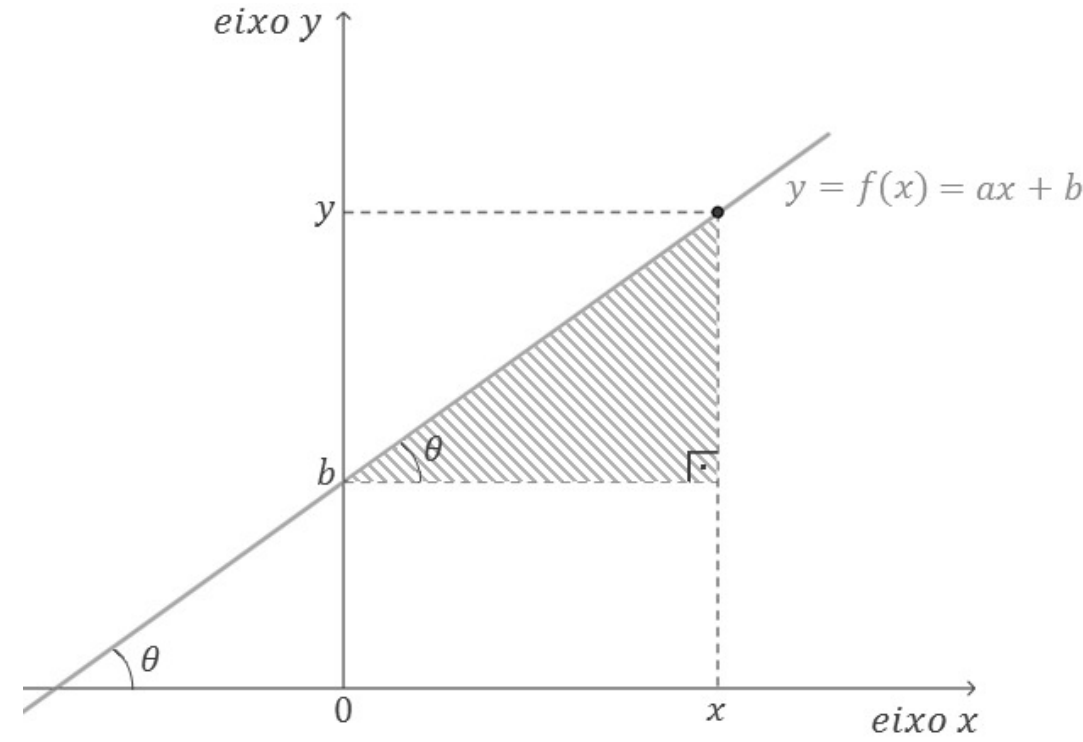

Figura 4: Gráfico de uma função afim $f(x)=a x+b, \operatorname{com} a>0$. 


\section{Um curso rápido de cálculo diferencial e integral para pré-universitários e calouros}

Agora, volte à Fig. 3, que mostra uma reta $t$ tangente ao gráfico de uma função $f(x)$, em um ponto $P$, como o limite de uma sequência de retas secantes. Procure enxergar que muito próximo do ponto $P$ o gráfico de $f(x)$ se confunde com a reta tangente $t$. Assim, partindo de $x=x_{P}$, uma variação infinitesimal $\mathrm{d} x$ em $x$ resulta em uma mesma variação infinitesimal $\mathrm{d} y \mathrm{em}$ $y$ tanto no gráfico de $f(x)$ como na reta $t$, e, portanto, a razão $\mathrm{d} y / \mathrm{d} x$, para $x=x_{P}$, é a mesma para o gráfico de $f(x)$ e para a reta $t^{5}$ Segue então que $f^{\prime}\left(x_{P}\right)=a$, em que $a$ é o coeficiente angular da reta $t$. Ou seja, a derivada de $f(x)$ no ponto $x=x_{P}$ é igual ao coeficiente angular da reta tangente ao gráfico de $f(x)$ no ponto de abscissa $x_{P}$. Como o coeficiente angular quantifica a inclinação da reta, também podemos dizer que a derivada de $f(x)$ no ponto $x=x_{P}$ é igual à inclinação da reta tangente ao gráfico de $f(x)$ no ponto de abscissa $x_{P}$.

Exemplo: Seja $f(x)=x^{2}$. Temos $f^{\prime}(x)=2 x$ e, portanto, $f^{\prime}(1)=2$. Logo, a reta tangente ao gráfico de $f(x)$ no ponto de abscissa 1 , de equação $y=a x+b$, tem coeficiente angular $a=2$. Obtemos o coeficiente linear $b$ dessa reta observando que o ponto $(1,1)$ do gráfico de $f(x)=x^{2}$ é também um ponto da reta. Portanto, temos: $1=2 \cdot 1+b \Longrightarrow b=-1$. Segue que a equação da reta tangente ao gráfico de $f(x)=x^{2}$ no ponto de abscissa 1 é $y=2 x-1$. É interessante usarmos algum software para traçar os gráficos de $f(x)=x^{2}$ e $g(x)=2 x-1$ (veja o resultado na Fig. 5).

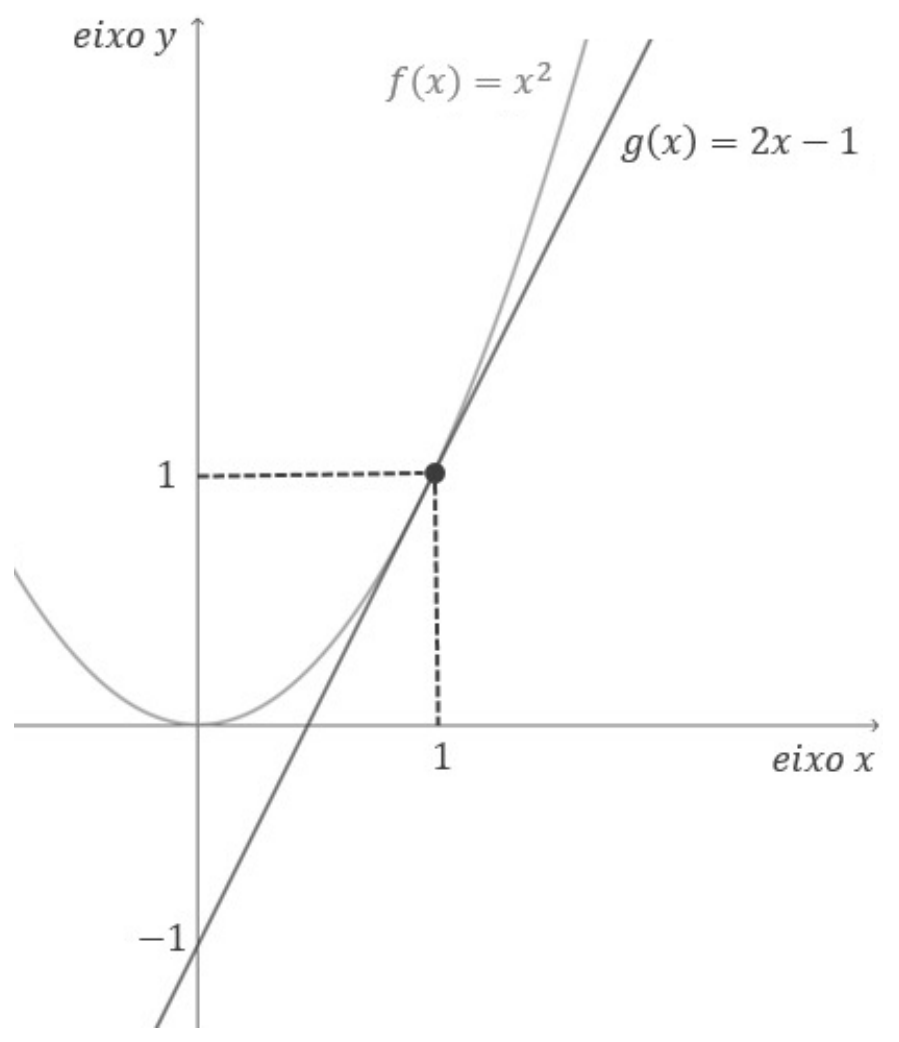

Figura 5: Gráficos das funções $f(x)=x^{2}$ e $g(x)=2 x-1$. A reta de equação $y=2 x-1$ é tangente ao gráfico de $f$ no ponto de abscissa 1 .

Sugerimos que você resolva agora o Exercício 16.

\footnotetext{
${ }^{5}$ Lembre-se que sempre que trabalhamos com a razão entre duas quantidades infinitesimais, há um limite implícito. Temos $\mathrm{d} y / \mathrm{d} x=\lim _{\Delta x \rightarrow 0}(\Delta y / \Delta x)$. Perceba que fazer $\Delta x$ tender a 0 corresponde a fazer a sequência de retas secantes da Fig. 3 tender à reta tangente $t$.
} 


\section{Aplicações da derivada}

\section{Taxas de variação e retas tangentes}

Cálculos de taxas de variação e obtenção de equações de retas tangentes a gráficos de funções são duas aplicações óbvias da derivada. Sugerimos que mesmo que você tenha compreendido bem esses tópicos na seção "A derivada", faça agora uma pausa no estudo deste material e resolva os Exercícios 17 a 25 (envolvendo taxas de variação), e 26 a 29 (envolvendo retas tangentes).

\section{Análise de gráficos de funções}

A Fig. 6 mostra o gráfico da posição $s$ de uma partícula em função do tempo $t$, para $t \geq 0$. Usando o que aprendemos na seção "A derivada como o coeficiente angular da reta tangente" podemos extrair desse gráfico informações sobre a velocidade $v$ da partícula.

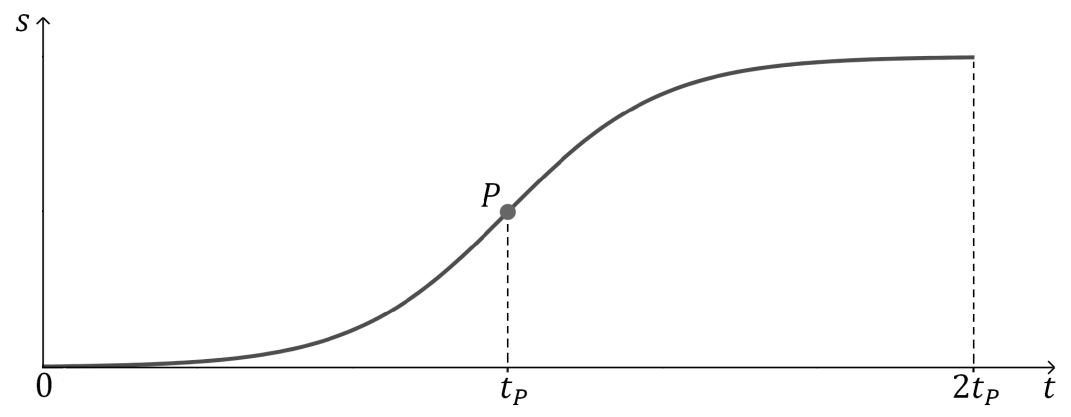

Figura 6: Gráfico da posição $s$ de uma partícula em função do tempo $t$.

Lembre-se que $v=\mathrm{d} s / \mathrm{d} t$ (ou seja, a velocidade da partícula é igual à derivada de sua posição em relação ao tempo) e, portanto, $v(t)$ é igual ao coeficiente angular da reta tangente ao gráfico de $s(t)$, no instante $t$. Assim, observando na Fig.6 como a inclinação da reta tangente ao gráfico de $s(t)$ muda com $t$ podemos concluir que a velocidade da partícula, praticamente nula em $t=0$, vai aumentando até alcançar seu valor máximo em $t=t_{P}$, e então começa a diminuir (de forma simétrica), voltando a ser praticamente nula no instante $t=2 t_{P}$.

Dizemos que o ponto $P$ do gráfico de $s(t)$ na Fig.6é um ponto de inflexão: um ponto de mudança de concavidade (neste caso, a curva muda de côncava para cima para côncava para baixo quando cruzamos o ponto $P$ da esquerda para a direita).

Apesar das informações que obtivemos, esboçar o gráfico de $v(t)$ a partir do gráfico de $s(t)$ não é algo trivial como pode parecer. Através de um outro exemplo, vamos explicar por quê.

A Fig.7 mostra os gráficos das posições de três partículas, em função do tempo. Inicialmente em repouso, elas partem de um mesmo ponto no instante $t_{i}$, se separam (pelas formas distintas como suas velocidades aumentam) e voltam a se encontrar no instante $t_{f}$. Perceba que $v_{3}\left(t_{f}\right)>v_{2}\left(t_{f}\right)>v_{1}\left(t_{f}\right)$. A Fig. 8 mostra os gráficos das velocidades das partículas da Fig. 7 . Como esperado, todas as velocidades aumentam de 0 , no instante $t_{i}$, a um valor máximo no instante $t_{f}$ (considerando-se o intervalo $\left[t_{i}, t_{f}\right]$ ), mas as formas como ocorrem esses aumentos - reveladas na Fig. 8 - não são trivialmente extraídas através de uma simples observação da Fig. $7^{6}$ Portanto, esboçar o gráfico de $v(t)$ a partir do gráfico de $s(t)$ (ou de $f^{\prime}(x)$ a partir do

\footnotetext{
${ }^{6}$ Geramos os gráficos da Fig.7 $\operatorname{com} s_{1}(t)=t^{3 / 2}, s_{2}(t)=t^{2}$ e $s_{3}(t)=t^{5 / 2}$ (no SI). Derivando essas funções, obtemos, respectivamente, $v_{1}(t)=\frac{3}{2} t^{1 / 2}, v_{2}(t)=2 t$ e $v_{3}(t)=\frac{5}{2} t^{3 / 2}$ (no SI) - expressões que usamos para gerar os gráficos da Fig.8.8.
} 
gráfico de $f(x))$ não é, em geral, algo trivial.

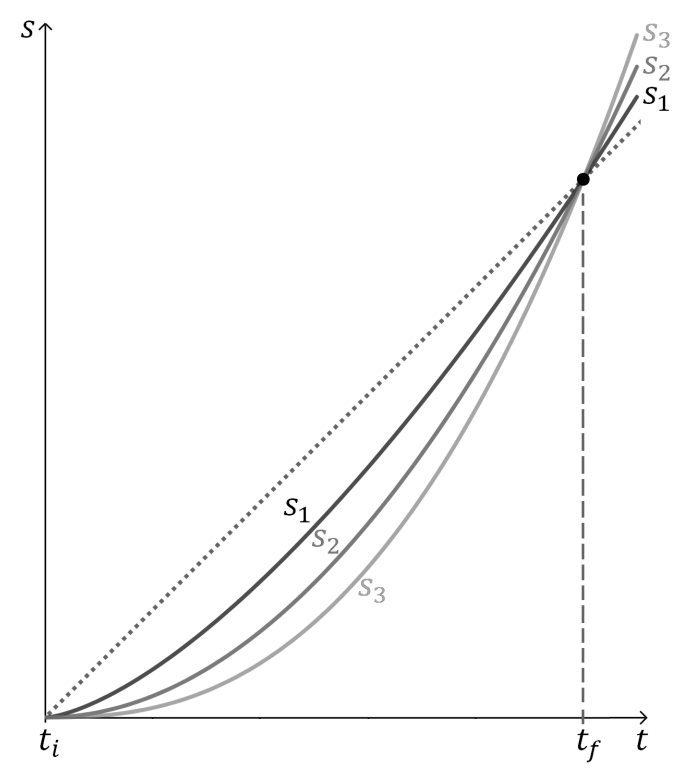

Figura 7: Posições $s_{1}, s_{2}$ e $s_{3}$ de três partículas, em função do tempo $t$. A linha pontilhada foi incluída para deixar mais nítidas as curvaturas dos três gráficos.

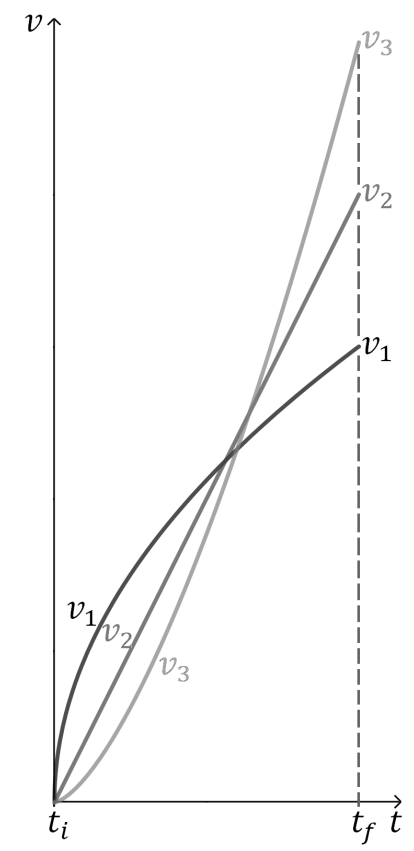

Figura 8: Velocidades $v_{1}, v_{2}$ e $v_{3}$, em função do tempo $t$, das três partículas da Fig.7.7.

\section{Problemas envolvendo mínimos ou máximos locais}

Uma das aplicações mais interessantes da derivada está em seu uso para a resolução de certos problemas de otimização. É o que exploraremos nesta seção.

A Fig. 9a exibe o gráfico de uma função que apresenta um ponto que chamamos (por razões óbvias) de mínimo local, enquanto na Fig.9p temos um máximo local e nas Figs.98 e 9d temos pontos de inflexão (que são pontos de mudança de concavidade (veja a seção "Análise de gráficos de funções")). O que há em comum nesses quatro pontos? Neles, a reta tangente ao gráfico da função é paralela ao eixo das abscissas, e, portanto, ali a derivada da função é nula. 
Seja $f(x)$ uma função cujo gráfico desconhecemos. Procure visualizar que se $f^{\prime}(x)=0$ em $x=x_{P}$, mas é não nula na vizinhança imediata de $x_{P}$, então o ponto $P$, de abscissa $x_{P}$, é um ponto de mínimo local, de máximo local ou de inflexão. Mas como saber qual é o caso? A primeira coisa que fazemos é examinar o sinal da derivada segunda de $f(x)$ para $x=x_{P}$ :

se $f^{\prime \prime}\left(x_{P}\right)>0$, trata-se de um ponto de mínimo local;

se $f^{\prime \prime}\left(x_{P}\right)<0$, trata-se de um ponto de máximo local;

se $f^{\prime \prime}\left(x_{P}\right)=0$, nada podemos concluir com este teste. 7

Como podemos chegar às duas primeiras conclusões acima? Vejamos. Se $f^{\prime \prime}\left(x_{P}\right)>0$ - que podemos reescrever como $\left.\left(\mathrm{d} f^{\prime}(x) / \mathrm{d} x\right)\right|_{x=x_{P}}>0$ - então a taxa de variação de $f^{\prime}(x)$ é positiva para $x=x_{P}$, e isso significa que $f^{\prime}(x)$ cresce ao cruzarmos o ponto $P$, e assim a reta tangente ao gráfico de $f(x)$ gira no sentido anti-horário ao cruzarmos o ponto $P$. E isso nos leva à conclusão que o ponto $P$ é um ponto de mínimo local. De forma semelhante, podemos concluir que se $f^{\prime \prime}\left(x_{P}\right)<0$ então o ponto $P$ é um ponto de máximo local.

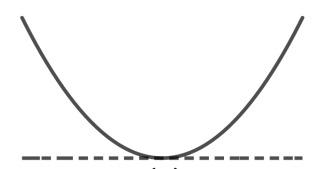

(a)

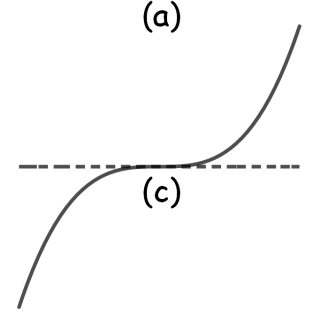

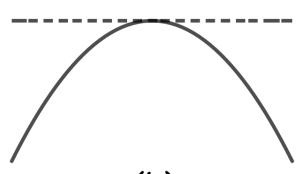

(b)

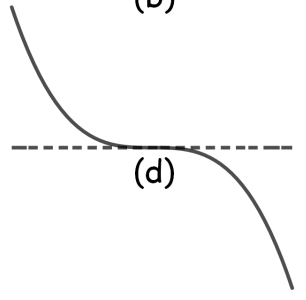

Figura 9: Exemplos de mínimo local, máximo local e pontos de inflexão em gráficos de funções, com as respectivas retas tangentes. Os eixos $x$ e $y$ foram omitidos.

Mínimos locais frequentemente são também mínimos globais. Procure visualizar que se $f^{\prime}(x)=0$ apenas para um determinado número $x_{P}$ do domínio de $f$, e se temos $f^{\prime \prime}\left(x_{P}\right)>0$, então o ponto $P$ de abscissa $x_{P}$ é, além de um mínimo local, também um mínimo global; ou seja, para todos os demais valores de $x$ temos $\left.f(x)>f\left(x_{P}\right)\right]^{8}$ É que, sendo a função $f$ bem comportada, para que existisse um valor de $f(x)$ que fosse menor que $f\left(x_{P}\right)$ (sendo $f^{\prime}\left(x_{P}\right)=0$ e $f^{\prime \prime}\left(x_{P}\right)>0$ ) o gráfico de $f$ teria que apresentar ao menos um ponto de máximo local (como ilustra a Fig.10, mas estamos considerando, aqui, que $f^{\prime}(x)=0$ apenas para $x=x_{P}$, e neste caso temos, portanto, a garantia de que o ponto de mínimo local, com abscissa $x=x_{P}$, é também um ponto de mínimo global.

\footnotetext{
${ }^{7}$ Neste caso, devemos recorrer a algum outro método para identificar se o ponto $P$ é um ponto de mínimo local, de máximo local ou de inflexão. Exploraremos um exemplo simples no Exercício 38.

${ }^{8}$ Para o leitor avançado: estamos supondo aqui, é claro, que a função $f$ e sua derivada são contínuas, e que seu domínio é algum intervalo (aberto ou fechado) único, em vez de um conjunto de intervalos disjuntos.
} 


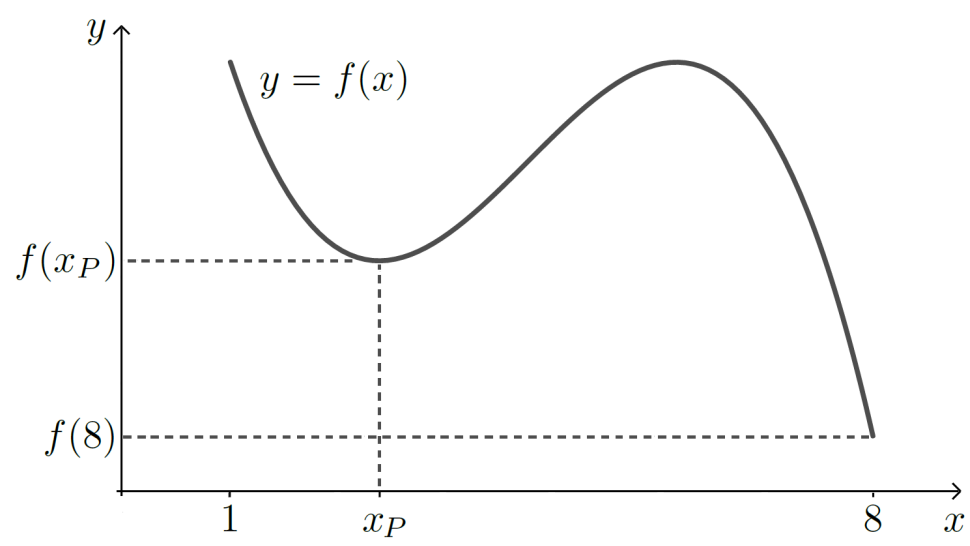

Figura 10: Gráfico de uma função $f(x)$, definida no intervalo $[1,8]$, cujo mínimo global é $f(8)$ - não coincidindo, portanto, com o mínimo local $f\left(x_{P}\right)$.

Analogamente, máximos locais frequentemente são também máximos globais. Procure visualizar que se $f^{\prime}(x)=0$ apenas para um determinado número $x_{P}$ do domínio de $f$, e se temos $f^{\prime \prime}\left(x_{P}\right)<0$, então o ponto $P$ de abscissa $x_{P}$ é, além de um máximo local, também um máximo global; ou seja, para todos os demais valores de $x$ temos $f(x)<f\left(x_{P}\right)$.

Agora vamos fazer uso do que aprendemos até aqui nesta seção para resolver um interessante problema de otimização: de todos os cilindros circulares retos com um mesmo volume $V$ (veja a Fig. 11), qual é o que possui a menor área A de superfície? ?

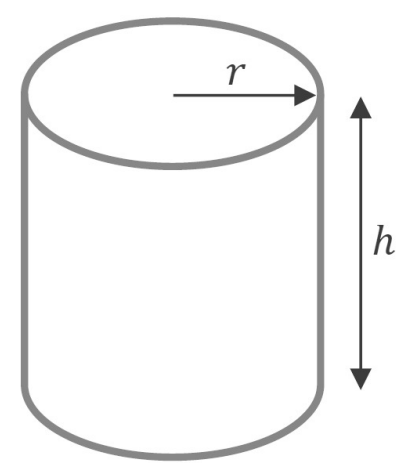

Figura 11: Cilindro circular reto de raio $r$ e altura $h$.

Temos $V=\pi r^{2} h$ e $A=2 \pi r^{2}+2 \pi r h$. Com $V$ constante, podemos expressar $h$ em função de $r: h=V /\left(\pi r^{2}\right)$. Com isso, podemos reescrever:

$$
A=2 \pi r^{2}+2 \pi r \frac{V}{\pi r^{2}}=2 \pi r^{2}+\frac{2 V}{r} .
$$

Temos, agora, $A=A(r)$. No caso geral temos $A=A(r, h)$, mas a restrição a um volume $V$ constante nos permitiu relacionar $h$ e $r$, e assim obtivemos $A$ como uma função de $r$, apenas. Temos:

$$
\frac{\mathrm{d} A}{\mathrm{~d} r}=0 \Longrightarrow 4 \pi r-\frac{2 V}{r^{2}}=0 \Longrightarrow r=\left(\frac{V}{2 \pi}\right)^{\frac{1}{3}} .
$$

Logo, $\mathrm{d} A / \mathrm{d} r=0$ apenas para $r=(V / 2 \pi)^{1 / 3}$. Temos:

\footnotetext{
${ }^{9}$ Este problema é de interesse prático, se pensarmos em fabricar um cilindro para armazenar algum volume fixo de líquido, mas com o menor consumo possível de material (pois a quantidade de material usada é proporcional à área de superfície).
} 


$$
\frac{\mathrm{d}^{2} A}{\mathrm{~d} r^{2}}=\frac{\mathrm{d}}{\mathrm{d} r}\left(4 \pi r-\frac{2 V}{r^{2}}\right)=4 \pi+\frac{4 V}{r^{3}}
$$

e então $\mathrm{d}^{2} A / \mathrm{d} r^{2}$ é positiva para $r=(V / 2 \pi)^{1 / 3}$. Portanto, $A(r)$ possui um mínimo local, que é também um mínimo global, para $r=(V / 2 \pi)^{1 / 3}$. Ou seja, na família de infinitos cilindros com um mesmo volume $V$, existe um, e apenas um, com área mínima, e é o cilindro com raio $r=(V / 2 \pi)^{1 / 3}$. Vejamos qual é a relação entre $r$ e $h$ neste cilindro: resolvendo esta última igualdade para $V$, e substituindo a expressão resultante em $V=\pi r^{2} h$, obtemos:

$$
2 \pi r^{3}=\pi r^{2} h \Longrightarrow 2 r=h .
$$

Logo, de todos os cilindros circulares retos com um mesmo volume $V$, o que possui a menor área $A$ de superfície é aquele cujo diâmetro é igual à sua altura.

Sugerimos que você resolva agora os Exercícios 30 a 38.

\section{Antiderivadas ou primitivas}

Dizemos que $F(x)$ é uma antiderivada (ou primitiva) de uma função $f(x)$ se a derivada de $F(x)$ é $f(x)$.

Exemplo 1: $F(x)=x^{2}$ é uma antiderivada de $f(x)=2 x$, pois a derivada de $F(x)$ é $f(x)$.

Observe que utilizamos o artigo indefinido "uma" para antiderivada. O que isso sugere? Que a função $f(x)$ não possui apenas uma antiderivada. De fato, são também antiderivadas de $f(x)=$ 2x: $x^{2}+1, x^{2}-5, x^{2}+\pi$, concorda? Podemos então expressar as antiderivadas de $f(x)=2 x$ como $F(x)=x^{2}+C$, em que $C$ é uma constante arbitrária. Portanto, $f(x)=2 x$ tem infinitas antiderivadas: uma para cada valor $\operatorname{de} C$ em $F(x)=x^{2}+C$.

O nível de dificuldade no cálculo de antiderivadas pode ir do trivial ao extremamente difícil. Em geral, o cálculo de antiderivadas é a parte mais árdua de uma primeira disciplina de cálculo diferencial e integral, em seu formato padrão. Há uma coleção de técnicas (denominadas técnicas de integração) que os estudantes aprendem, mas, mesmo assim, "sacadas" espetaculares podem ser necessárias para que se encontre as antiderivadas $F(x)$ de uma determinada função $f(x)$. Não iremos explorar essas técnicas neste texto, que tem caráter introdutório. Todas as antiderivadas com que iremos nos deparar aqui (incluindo os exercícios) serão obtidas por inspeção: ${ }^{10}$ olharemos para a expressão que define $f(x)$ e, usando nosso conhecimento de cálculo de derivadas, tentaremos descobrir a expressão geral para as funções $F(x)$ cujas derivadas são iguais a $f(x)$ (lembrando que aquelas funções só diferem entre si pelo valor de uma constante aditiva).

Exemplo 2: Quais são as antiderivadas de $f(x)=x^{5}$ ? Uma primeira tentativa poderia ser $F(x)=x^{6}+C$, mas ao calcularmos a derivada desta função obtemos $F^{\prime}(x)=6 x^{5}$, em vez de $x^{5}$. Contudo, podemos facilmente corrigir nossa tentativa inicial: $F(x)=x^{6} / 6+C$. Agora sim, obtemos $F^{\prime}(x)=6 x^{5} / 6=x^{5}=f(x)$

Exemplo 3: Quais são as antiderivadas de $g(x)=6 /(1+2 x)^{2}$ ? Este exemplo não é dos mais triviais, mas está longe de ser difícil. Que tal começarmos reescrevendo: $g(x)=6(1+2 x)^{-2}$ ? Daí, lembrando da regra da potência para o cálculo de derivadas, associada à regra da cadeia, uma primeira tentativa pode ser: $G(x)=(1+2 x)^{-1}+C$. Vamos testar: ${ }^{12}$

$$
G^{\prime}(x)=-(1+2 x)^{-2} \cdot 2=-2(1+2 x)^{-2} .
$$

\footnotetext{
${ }^{10} \mathrm{Na}$ verdade, haverá uma exceção: na seção “A integral indefinida”. Mas com um propósito que ficará claro.

${ }^{11}$ Perceba que se $f(x)=x^{n}$, com $n \neq-1$, então $F(x)=\frac{x^{n+1}}{n+1}+C$.

${ }^{12}$ Perceba o uso da regra da cadeia, no cálculo de $G^{\prime}(x)$.
} 
Chegamos bem perto, mas queremos o fator “6”, em vez do fator “-2”, na última expressão acima. Fica fácil corrigir isto: basta colocarmos o fator " -3 " na expressão para $G(x)$ (pois $-3 \cdot(-2)=6$ ), obtendo $G(x)=-3(1+2 x)^{-1}+C$. Verificando:

$$
G^{\prime}(x)=\left[-3(1+2 x)^{-1}+C\right]^{\prime}=3(1+2 x)^{-2} \cdot 2=6 /(1+2 x)^{2}=g(x) .
$$

Portanto, as antiderivadas de $g(x)=6 /(1+2 x)^{2}$ são

$$
G(x)=\frac{-3}{1+2 x}+C .
$$

Com alguma prática, a maior parte do desenvolvimento acima (ou até todo ele) pode ser feita mentalmente.

Exemplo 4: Agora vamos explorar uma aplicação à física. A velocidade de uma partícula, movendo-se ao longo de uma reta, varia com o tempo segundo $v(t)=3 t^{4}$, com $t$ em segundos e $v$ em metros por segundo. Considere que isto é tudo o que sabemos sobre o movimento da partícula. Pois bem, seja $s(t)$ a posição desta partícula, em função do tempo. Como $v(t)=\mathrm{d} s / \mathrm{d} t$, $s(t)$ é uma antiderivada de $v(t)$. Assim, temos:

$$
v(t)=3 t^{4} \Longrightarrow s(t)=\frac{3}{5} t^{5}+C(\text { no SI) }
$$

A constante $C$ é a posição da partícula no instante $\mathrm{t}=0: s(0)=C$. Portanto, é mais interessante usarmos " $s_{0}$ ", em vez de “ $C$ ". Temos, então:

$$
s(t)=s_{0}+\frac{3}{5} t^{5}(\text { no SI). }
$$

Não conhecemos o valor da posição inicial $\left(s_{0}\right)$ da partícula deste exemplo, já que tudo o que sabemos é como sua velocidade varia com o tempo, mas a expressão para $s(t)$ que obtivemos nos permite calcular o deslocamento sofrido pela partícula entre dois instantes $t_{1}$ e $t_{2}$ quaisquer:

$$
\Delta s=s\left(t_{2}\right)-s\left(t_{1}\right)=\left(x_{Q}+\frac{3}{5} t_{2}^{5}\right)-\left(x_{Q}+\frac{3}{5} t_{1}^{5}\right)=\frac{3}{5}\left(t_{2}^{5}-t_{1}^{5}\right) \text { (no SI). }
$$

Sugerimos que você resolva agora os Exercícios 39 a 43 .

\section{A integral definida}

\section{A integral definida como uma soma}

Através de uma série de exemplos, exploraremos informalmente o conceito de integral definida como uma soma de infinitos termos infinitesimais.

Exemplo 1: Sugerimos que você revise a seção "Tentando preencher um círculo com triângulos, e calculando sua área!". Fez isso? Muito bem, podemos imaginar o círculo de raio $R$ da Fig.2 preenchido por infinitos triângulos de base infinitesimal ds e altura $R$ (a Fig.12 ilustra um desses triângulos) ${ }^{13}$ A área de cada triângulo é

$$
\mathrm{d} a=\frac{(\mathrm{d} s) R}{2}=\frac{1}{2} R \mathrm{~d} s .
$$

\footnotetext{
${ }^{13}$ É claro, um círculo não pode ser preenchido por triângulos, mas, ao usarmos triângulos de base infinitesimal, implicitamente estamos tomando o limite em que o número de triângulos usados tende a infinito (como fizemos explicitamente na seção “Tentando preencher um círculo com triângulos, e calculando sua área!”), e isso nos leva, exatamente, à área do círculo.
} 


\section{Um curso rápido de cálculo diferencial e integral para pré-universitários e calouros}

Obtemos a área $A_{C}$ do círculo somando (ou "integrando") as áreas de todos os infinitos triângulos de base infinitesimal que o preenchem, e denotamos tal soma escrevendo:

$$
A_{C}=\int_{\text {círculo }} \mathrm{d} a=\int_{\text {círculo }} \frac{1}{2} R \mathrm{~d} s .
$$

Como o fator $R / 2$ é constante, pode ser posto em evidência, e então temos:

$$
A_{C}=\frac{1}{2} R \underbrace{\int_{\text {círculo }} \mathrm{d} s}_{2 \pi R}=\frac{1}{2} R \cdot 2 \pi R=\pi R^{2} .
$$

No desenvolvimento acima, $\int_{\text {círculo }} \mathrm{d} s$ denota a soma dos comprimentos infinitesimais $\mathrm{d} s$ ao longo do contorno do círculo, e essa soma, é claro, é igual ao comprimento desse contorno - ou seja, $2 \pi R$.

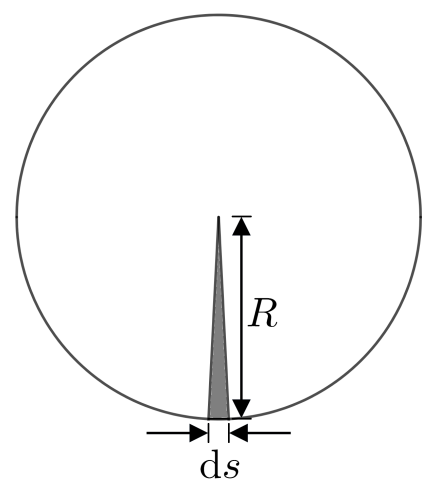

Figura 12: Triângulo de base infinitesimal $\mathrm{d} s$ e altura $R$, usado como elemento de área para o cálculo da área do círculo de raio $R$.

Exemplo 2: Agora, vamos mudar o elemento de área usado para o cálculo da área $A_{C}$ do círculo. Em vez de trabalharmos com triângulos de base infinitesimal, vamos trabalhar com coroas circulares de raio interno $r$ e raio externo $r+\mathrm{d} r$ (a Fig.13 ilustra uma dessas coroas), com $r$ variando de 0 a $R$. Visualize o círculo preenchido por infinitas coroas concêntricas, de espessura $\mathrm{d} r$, cada. A área infinitesimal de uma coroa circular com raio interno $r$ e raio externo $r+\mathrm{d} r$ é

$$
\mathrm{d} a=2 \pi r \mathrm{~d} r .
$$

Chegamos a essa expressão realizando um "corte" radial na coroa da Fig.13, e então "abrindo-a" de forma a obtermos um retângulo de base $2 \pi r$ e altura $\mathrm{d} r$. É claro, isso não poderia ser feito com uma coroa finita, devido à diferença de comprimento entre as circunferências interna e externa, mas no caso de uma coroa infinitesimal essa diferença $(\mathrm{d} r)$ é absolutamente desprezível. ${ }^{14}$

Obtemos a área $A_{C}$ do círculo integrando as áreas de todas as infinitas coroas circulares de espessura $\mathrm{d} r$ que o preenchem:

$$
A_{C}=\int_{\text {círculo }} \mathrm{d} a=\int_{\text {círculo }} 2 \pi r \mathrm{~d} r=2 \pi \int_{0}^{R} r \mathrm{~d} r .
$$

\footnotetext{
${ }^{14}$ Se você quer um pouco mais de rigor, observe que com o procedimento descrito obtemos, em vez de um retângulo de base $2 \pi r$ e altura $\mathrm{d} r$, um trapézio de base maior $2 \pi(r+\mathrm{d} r)$, base menor $2 \pi r$ e altura $\mathrm{d} r$. Esse trapézio tem área $\mathrm{d} a=[2 \pi(r+\mathrm{d} r)+2 \pi r] \mathrm{d} r / 2$, mas como $\mathrm{d} r$ é uma quantidade infinitesimal, podemos substituir $r+\mathrm{d} r$ por $r$, e isso resulta em $\mathrm{d} a=2 \pi r \mathrm{~d} r$.
} 
Nesta última expressão, as quantidades 0 e $R$ - respectivamente abaixo e acima do sinal de integração $\left(\int\right)$ - são denominadas "limites de integração", e determinam o intervalo para a variável de integração $r$; ou seja, estamos fazendo $r$ variar de 0 a $R$.

Pois bem, ainda não sabemos calcular $\int_{0}^{R} r \mathrm{~d} r$ (que, a propósito, lemos como "integral de $r \mathrm{~d} r$, de 0 a $R$ "). São infinitos termos $r \mathrm{~d} r$, e cada um deles depende do valor de $r$. Mas o que nos interessa, nesta seção, é explorar o conceito de integral definida, e trabalharemos mais alguns exemplos. Como calcular a integral deste exemplo, e dos próximos, veremos na seção "O teorema fundamental do cálculo".

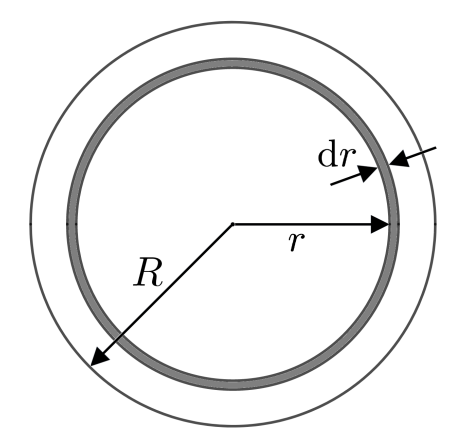

Figura 13: Coroa circular de raio interno $r$ e raio externo $r+\mathrm{d} r$, usada como elemento de área para o cálculo da área do círculo de raio $R$.

Exemplo 3: A Fig. 14 mostra um bloco que sofre um deslocamento horizontal $\Delta x=x_{2}-x_{1}$ sob a ação de uma força $F$ também horizontal. ${ }^{15}$ Se $F$ é constante, o trabalho dessa força, ao longo do deslocamento $\Delta x$, é $W=F \Delta x$ (estamos supondo que você está familiarizado com o cálculo de trabalhos de forças constantes). Mas se $F$ varia com $x$, como calculamos esse trabalho? A ideia é dividirmos o deslocamento $\Delta x$ em uma sequência de deslocamentos infinitesimais $\mathrm{d} x$. Como $F(x)$ é essencialmente constante ao longo de um deslocamento infinitesimal $\mathrm{d} x$, temos o trabalho infinitesimal $\mathrm{d} W=F(x) \mathrm{d} x$ entre as posições $x$ e $x+\mathrm{d} x$, e então obtemos o trabalho $W$ de $F$ ao longo do deslocamento $\Delta x=x_{2}-x_{1}$ integrando todos os trabalhos infinitesimais $\mathrm{d} W$ :

$$
W=\int_{x=x_{1}}^{x=x_{2}} \mathrm{~d} W=\int_{x_{1}}^{x_{2}} F(x) \mathrm{d} x .
$$

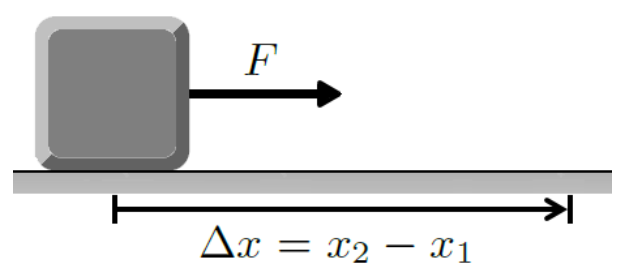

Figura 14: Bloco sofrendo um deslocamento $\Delta x=x_{2}-x_{1}$ sob a ação de uma força horizontal $F$.

Por exemplo, com $F(x)=\left(6 \mathrm{~N} / \mathrm{m}^{2}\right) x^{2}, x_{1}=0$ e $x_{2}=1 \mathrm{~m}$ temos

$$
W=\int_{0}^{1} 6 x^{2} \mathrm{~d} x \quad(\text { no SI }) .
$$

\footnotetext{
${ }^{15}$ Estamos dispensando a notação vetorial, aqui, porque o problema é unidimensional.
} 


\section{Um curso rápido de cálculo diferencial e integral para pré-universitários e calouros}

Veremos como calcular esta integral na seção "O teorema fundamental do cálculo". Mas observe que o cálculo da integral é apenas a parte final do desenvolvimento; montar a integral constitui uma etapa cheia de significado!

Exemplo 4: Vamos revisitar o Exemplo 4 da seção "Antiderivadas ou primitivas", mas desta vez explorando o conceito de integral definida. Temos:

$$
v(t)=\frac{\mathrm{d} s}{\mathrm{~d} t} \Longrightarrow \mathrm{d} s=v(t) \mathrm{d} t \Longrightarrow \int_{s_{0}}^{s} \mathrm{~d} \tilde{s}=\int_{0}^{t} v(\tilde{t}) \mathrm{d} \tilde{t} .
$$

Vamos discutir bem esta última igualdade. No primeiro membro estamos integrando os deslocamentos infinitesimais d $\tilde{s}$ de $s_{0}$ a $s$, e isso dá $s-s_{0}$. Usamos " $\tilde{s}$ " porque preferimos reservar "s" para o limite de integração superior. No segundo membro, temos a integração dos mesmos deslocamentos infinitesimais, mas expressos como $v(\tilde{t}) \mathrm{d} \tilde{t}, \operatorname{com} \tilde{t}$ variando de 0 a $t$. É claro, $s_{0}$ é a posição da partícula no instante 0 , e $s$ é sua posição no instante $t$. Continuando, temos:

$$
s-s_{0}=\int_{0}^{t} v(\tilde{t}) \mathrm{d} \tilde{t} \Longrightarrow s=s_{0}+\int_{0}^{t} v(\tilde{t}) \mathrm{d} \tilde{t} .
$$

$\operatorname{Com} v(\tilde{t})=3 \tilde{t}^{4}$ (no SI), obtemos:

$$
s=s_{0}+\int_{0}^{t} 3 \tilde{t}^{4} \mathrm{~d} \tilde{t} \quad \text { (no SI) }
$$

Como você já sabe, calcularemos esta integral na seção "O teorema fundamental do cálculo".

Exemplo 5: A Fig. 15a apresenta o gráfico de $f(x)=\sqrt{x}$ e a região $\mathcal{R}$ sob a curva no intervalo $1 \leq x \leq 3$. Podemos calcular a área dessa região imaginando-a preenchida com retângulos de base infinitesimal $\mathrm{d} x$ (um desses retângulos está ilustrado na Fig. 15 b). É claro, não podemos preencher a região $\mathcal{R}$ com retângulos, mas ao trabalharmos com retângulos de base infinitesimal $\mathrm{d} x$ estamos, implicitamente, tomando o limite em que a base $\Delta x$ de cada retângulo usado tende a 0 , e com isso a área total dos retângulos tende à área daquela região (veja a Fig. 15c). Obtemos a área $A$ da região $\mathcal{R}$ integrando as áreas infinitesimais $\mathrm{d} a=f(x) \mathrm{d} x, \operatorname{com} x$ variando de 1 a 3 :

$$
A=\int_{x=1}^{x=3} \mathrm{~d} a=\int_{1}^{3} f(x) \mathrm{d} x=\int_{1}^{3} \sqrt{x} \mathrm{~d} x .
$$

Concluiremos na seção "O teorema fundamental do cálculo".

Exemplo 6: Neste exemplo final, vamos calcular a força exercida sobre uma partícula com carga elétrica $Q>0$ por uma barra delgada de comprimento $L$ com densidade linear de carga $\lambda$ positiva e constante 16 Como ilustra a Fig. 16a, a partícula está a uma distância $D$ da extremidade direita da barra. Você não precisa ter estudado eletrostática para compreender este exemplo. Basta saber que duas partículas com cargas elétricas $q_{1}$ e $q_{2}$, separadas por uma distância $r$, se repelem (se as cargas têm o mesmo sinal) ou se atraem (se as cargas têm sinais opostos) com uma força que tem a direção da reta que passa pelas partículas, e intensidade

$$
F=K \frac{\left|q_{1}\right|\left|q_{2}\right|}{r^{2}}
$$

\footnotetext{
${ }^{16}$ Por exemplo, uma densidade linear de carga constante $\lambda=5 \times 10^{-6} \mathrm{C} / \mathrm{cm}$ significa que cada centímetro da barra possui uma carga elétrica de $5 \times 10^{-6} \mathrm{C}$.
} 

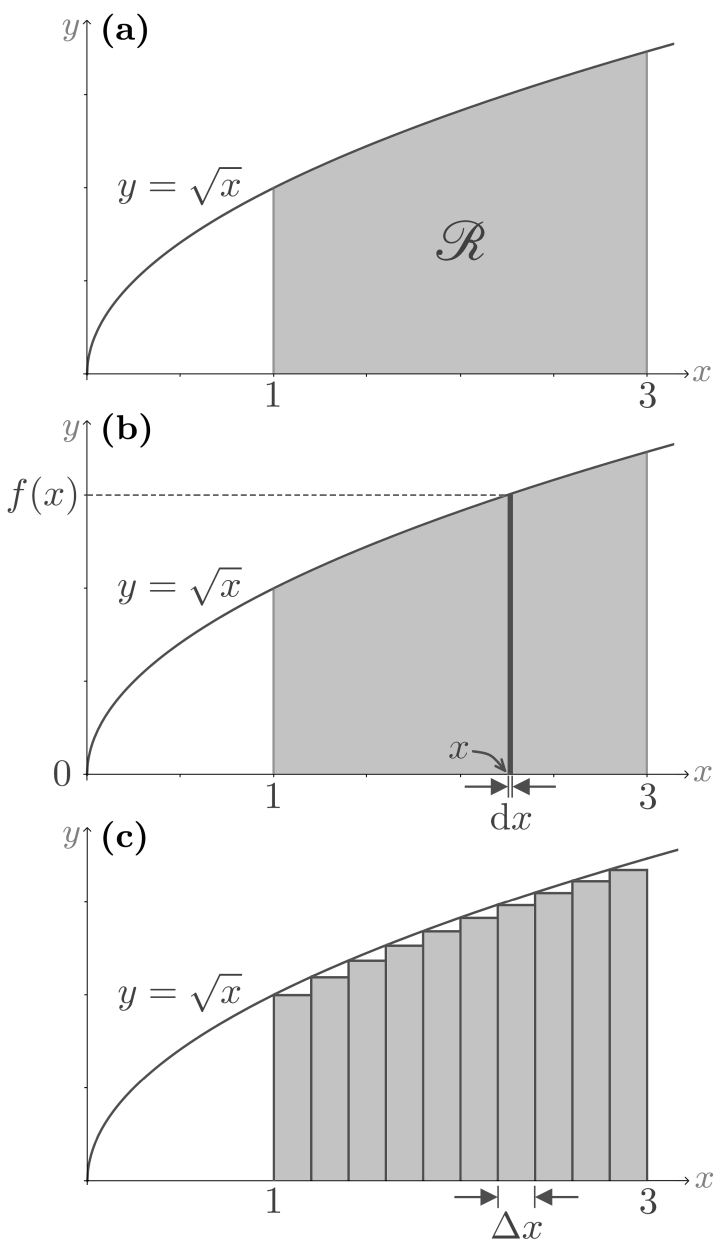

Figura 15: (a) Gráfico de $f(x)=\sqrt{x}$ e a região $\mathcal{R}$ entre a curva e o eixo $x$ no intervalo $[1,3]$. (b) Retângulo de base $\mathrm{d} x$ e altura $f(x)$ na região $\mathcal{R}$. (c) Tentando preencher a região $\mathcal{R}$ com retângulos de base $\Delta x$ : quando o número de retângulos usados tende a infinito, a área total dos retângulos tende à área $A$ da região $\mathcal{R}$.

em que $K$ é uma constante cujo valor aproximado é $K \approx 9 \times 10^{9} \mathrm{~N} \cdot \mathrm{m}^{2} / \mathrm{C}^{2}$ (sendo "C" - o coulomb - a unidade de carga elétrica no SI). Essa é a chamada lei de Coulomb. Mas como faremos uso da expressão acima para calcular a força que a barra da Fig. 16 a exerce sobre a partícula à sua direita? A estratégia é dividirmos a barra delgada em pedaços de comprimento infinitesimal $\mathrm{d} x$ (veja a Fig. $16 \mathrm{~b}$ ), porque cada um desses pedaços se comporta como uma partícula carregada, de carga $\mathrm{d} q=\lambda \mathrm{d} x$, e então podemos fazer uso da lei de Coulomb: a força infinitesimal $\mathrm{d} F$ exercida pela partícula de carga $\mathrm{d} q=\lambda \mathrm{d} x$, na posição $x$, sobre a partícula de carga $Q$ (veja a Fig. $16 p)$ é

$$
\mathrm{d} F=K \frac{Q \mathrm{~d} q}{r^{2}}=K \frac{Q(\lambda \mathrm{d} x)}{r^{2}}=K Q \lambda \frac{\mathrm{d} x}{(L+D-x)^{2}} .
$$

Obtemos a força $F$ integrando as forças infinitesimais $\mathrm{d} F$, com $x$ variando de 0 a $L:{ }^{17}$

$$
F=\int_{x=0}^{x=L} \mathrm{~d} F=\int_{0}^{L} K Q \lambda \frac{\mathrm{d} x}{(L+D-x)^{2}}=K Q \lambda \int_{0}^{L} \frac{\mathrm{d} x}{(L+D-x)^{2}} .
$$

Concluiremos este cálculo na seção "O teorema fundamental do cálculo".

\footnotetext{
${ }^{17}$ É claro, isso só dá certo devido à validade do princípio da superposição, que você deve conhecer.
} 

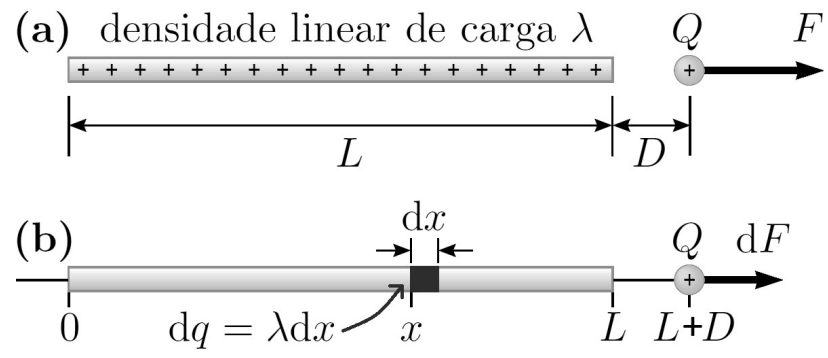

Figura 16: (a) Força exercida por uma barra delgada uniformemente carregada sobre uma partícula de carga $Q>0$. (b) Divisão da carga total da barra em elementos de carga $\mathrm{d} q=\lambda \mathrm{d} x$ para o cálculo da força $F$ por integração. A distância entre o elemento de carga d $q$ indicado e a partícula de carga $Q$ é $r=L+D-x$.

\section{O teorema fundamental do cálculo}

Em cada um dos Exemplos 2 a 6 da seção "A integral definida como uma soma" deixamos uma integral definida a ser calculada. Observe que podemos reescrevê-las na forma geral

$$
\int_{a}^{b} f(x) \mathrm{d} x .
$$

Mas como efetuar uma soma com infinitos termos infinitesimais? Veremos a seguir.

Vamos fazer, em (5),

$$
f(x) \mathrm{d} x=\mathrm{d} y .
$$

Ou seja, estamos introduzindo uma função $y(x)$ tal que a quantidade infinitesimal $f(x) \mathrm{d} x$ (que, a menos que $f(x)$ seja constante, depende do valor de $x$ ) é igual a uma variação infinitesimal dy em $y(x)$. Trata-se de uma ideia brilhante, porque com isso temos:

$$
\int_{a}^{b} \underbrace{f(x) \mathrm{d} x}_{\mathrm{d} y}=\int_{x=a}^{x=b} \mathrm{~d} y=y(b)-y(a) .
$$

Entenda que sendo $y$ uma função de $x$, a soma das variações infinitesimais dy, quando $x$ varia de $a$ a $b$, resulta na variação total $y(b)-y(a), 18$

Mas qual é essa função $y(x)$ ? Vejamos: dividindo ambos os membros da igualdade (6) por $\mathrm{d} x$ obtemos

$$
f(x)=\frac{\mathrm{d} y}{\mathrm{~d} x},
$$

e, portanto, $y(x)$ é uma função cuja derivada é $f(x)$; ou seja, $y(x)$ é uma antiderivada de $f(x)$, e assim convém usarmos " $F(x)$ ", em vez de “ $y(x)$ ”. Podemos então reescrever (7) como

$$
\int_{a}^{b} f(x) \mathrm{d} x=F(b)-F(a) .
$$

Esta igualdade, com a condição de continuidade da função $f$ no intervalo $[a, b], 19$ constitui o teorema fundamental do cálculo (TFC) 20

\footnotetext{
${ }^{18}$ Como sempre, estamos considerando apenas funções "bem comportadas".

${ }^{19}$ Basicamente, se uma função é contínua no intervalo $[a, b]$, seu gráfico nesse intervalo é uma linha contínua.

${ }^{20}$ Existe uma segunda parte do TFC, que não estamos apresentando aqui.
} 
Podemos reescrever a igualdade (8) como

$$
\int_{a}^{b} f(x) \mathrm{d} x=\left.F(x)\right|_{a} ^{b}
$$

Como veremos, o membro direito desta igualdade é uma notação muito útil para $F(b)-F(a)$.

Perceba que qual antiderivada usaremos para $F(x)$ não importa, porque elas diferem entre si apenas por uma constante arbitrária, e a diferença em (8) elimina qualquer constante aditiva. Veja:

$$
\int_{a}^{b} f(x) \mathrm{d} x=[F(b)+\mathcal{Q}]-[F(a)+\mathcal{Q}]=F(b)-F(a) .
$$

\section{Voltando aos Exemplos 2 a 6 da seção "A integral definida como uma soma"}

Agora vamos usar o TFC para calcular as integrais definidas que deixamos nos Exemplos 2 a 6.

Começando com o Exemplo 2, temos:

$$
A_{C}=2 \pi \int_{0}^{R} \underbrace{r}_{f(r)} \mathrm{d} r=\left.2 \pi \underbrace{\frac{r^{2}}{2}}_{F(r)}\right|_{0} ^{R}=\pi R^{2} .
$$

Passemos ao Exemplo 3. Temos, no SI:

$$
W=\int_{0}^{1} 6 x^{2} \mathrm{~d} x=\left.6 \frac{x^{3}}{3}\right|_{0} ^{1}=2 \text { joules }
$$

Agora, passemos ao Exemplo 4. Temos, no SI:

$$
s=s_{0}+\int_{0}^{t} 3 \tilde{t}^{4} \mathrm{~d} \tilde{t}=s_{0}+\left.3 \frac{\tilde{t}^{5}}{5}\right|_{0} ^{t}=s_{0}+\frac{3}{5} t^{5} \text { (no SI). }
$$

O mesmo resultado que obtivemos no Exemplo 4 da seção "Antiderivadas ou primitivas".

Concluindo o Exemplo 5:

$$
A=\int_{1}^{3} \sqrt{x} \mathrm{~d} x=\int_{1}^{3} x^{1 / 2} \mathrm{~d} x=\left.\frac{x^{3 / 2}}{3 / 2}\right|_{1} ^{3}=\frac{2}{3}\left(3^{3 / 2}-1\right) \approx 2,8
$$

Dê uma olhada na Fig.15, e veja se acha este resultado razoável.

Por fim, o Exemplo 6:

$$
\begin{aligned}
F & =K Q \lambda \int_{0}^{L} \frac{\mathrm{d} x}{(L+D-x)^{2}}=K Q \lambda \int_{0}^{L}(L+D-x)^{-2} \mathrm{~d} x=\left.K Q \lambda(L+D-x)^{-1}\right|_{0} ^{L} \\
& =\left.K Q \lambda \frac{1}{L+D-x}\right|_{0} ^{L}=K Q \lambda\left(\frac{1}{D}-\frac{1}{L+D}\right) .
\end{aligned}
$$

Todos esses resultados são incríveis, não acha?

Sugerimos que você resolva agora o Exercício 44. 


\section{Aplicações da integral definida}

Preparamos uma série de exercícios envolvendo aplicações diversas da integral definida: os Exercícios 45 a 60. Não deixe de resolvê-los.

\section{A integral indefinida}

Antiderivadas ou primitivas são também chamadas de integrais indefinidas. Mas quando esta expressão é usada, geralmente vem acompanhada da seguinte notação para as antiderivadas $F(x)$ de uma função $f(x)$ :

$$
\int f(x) \mathrm{d} x
$$

Assim, por exemplo,

$$
\int x^{2} \mathrm{~d} x=\frac{x^{3}}{3}+C
$$

Contudo, quando físicos e engenheiros escrevem uma integral, quase sempre é uma integral definida (que, informalmente, é uma soma de infinitos termos infinitesimais), e na igualdade acima o membro esquerdo não denota uma soma, mas uma função de $x$ - o que é muito estranho, não acha?

Mas há uma forma de dar sentido a essa notação. Em vez de encararmos a expressão em (9) como uma notação para $F(x)$, vamos defini-la da seguinte forma: 21

$$
\int f(x) \mathrm{d} x \equiv F(a)+\int_{a}^{x} f(t) \mathrm{d} t .
$$

Ou seja, encare o membro esquerdo de (10) como uma notação para o membro direito - que é uma função de $x$, concorda $\sqrt{22}$ Aplicando o TFC à integral definida em 10 obtemos

$$
\int f(x) \mathrm{d} x \equiv F(a)+\underbrace{\int_{a}^{x} f(t)}_{F(x)-F(a)} \mathrm{d} t=F(x),
$$

e então temos

$$
\int f(x) \mathrm{d} x \equiv F(a)+\int_{a}^{x} f(t) \mathrm{d} t=F(x) .
$$

Entendeu bem o que fizemos acima? Em vez de trabalharmos com a expressão em (9) como uma notação para $F(x)$, optamos por trabalhar com aquela expressão como uma notação para a expressão no segundo membro de $(10)$, que nos dá, com a aplicação do TFC, $F(x)$. Tudo isso está reunido em (11).

Em casos simples como o exemplo do início desta seção, em que conseguimos obter as antiderivadas de $f(x)$ por inspeção, a notação apresentada nesta seção não se mostra útil, mas na maioria das vezes ela nos dá poder de cálculo. Vejamos um exemplo.

Exemplo: Vamos obter as antiderivadas $F(x)$ de

$$
f(x)=x \sqrt{1-x}(x<1) .
$$

\footnotetext{
${ }^{21}$ Podemos ler o sinal "三” assim: "é definido(a) como".

${ }^{22} \mathrm{Em} \sqrt{10}, t$ não denota tempo, é claro; trata-se apenas de nossa escolha para a variável de integração.
} 


\section{Um curso rápido de cálculo diferencial e integral para pré-universitários e calouros}

Por inspeção, não é trivial (quer tentar?). Vejamos então o que conseguimos fazendo uso da sentença em (11).

$$
F(x)-F(a)=\int_{a}^{x} f(t) \mathrm{d} t=\int_{a}^{x} t \sqrt{1-t} \mathrm{~d} t,
$$

$\operatorname{com} x<1$ e $a<1$. Vamos introduzir a variável

$$
u=1-t
$$

e com isso temos:

- $t \sqrt{1-t}=(1-u) \sqrt{u}=(1-u) u^{1 / 2}=u^{1 / 2}-u^{3 / 2}$

- $\frac{\mathrm{d} u}{\mathrm{~d} t}=-1 \Longrightarrow \mathrm{d} t=-\mathrm{d} u$

- $t \sqrt{1-t} \mathrm{~d} t=\left(u^{1 / 2}-u^{3 / 2}\right)(-\mathrm{d} u)=\left(u^{3 / 2}-u^{1 / 2}\right) \mathrm{d} u$

- $t=a \Longrightarrow u=1-a$;

- $t=x \Longrightarrow u=1-x$.

Podemos então reescrever (13) como

$$
\begin{aligned}
F(x)-F(a) & =\int_{1-a}^{1-x}\left(u^{3 / 2}-u^{1 / 2}\right) \mathrm{d} u=\left.\left(\frac{u^{5 / 2}}{5 / 2}-\frac{u^{3 / 2}}{3 / 2}\right)\right|_{1-a} ^{1-x} \\
& =\left(\frac{2}{5}(1-x)^{\frac{5}{2}}-\frac{2}{3}(1-x)^{\frac{3}{2}}\right)-\left(\frac{2}{5}(1-a)^{\frac{5}{2}}-\frac{2}{3}(1-a)^{\frac{3}{2}}\right)
\end{aligned}
$$

Segue então que

$$
F(x)=\frac{2}{5}(1-x)^{\frac{5}{2}}-\frac{2}{3}(1-x)^{\frac{3}{2}}+C .
$$

Fica como exercício para você verificar que

$$
F^{\prime}(x)=f(x)=x \sqrt{1-x} .
$$

Você percebeu que fazer a substituição do limite de integração inferior $(1-a)$ na expressão

$$
\frac{u^{5 / 2}}{5 / 2}-\frac{u^{3 / 2}}{3 / 2}
$$

foi uma certa perda de tempo? Afinal, extraímos da expressão subsequente apenas a expressão resultante da substituição do limite de integração superior $(1-x)$, concorda? Então poderíamos ter trabalhado, desde o início, com $x$, em vez de $t$, e omitido os limites de integração. E a notação em (11) já é totalmente adequada para isso. Vamos mostrar, refazendo as contas acima para a obtenção de $F(x)$.

$$
F(x)=\int f(x) \mathrm{d} x=\int x \sqrt{1-x} \mathrm{~d} x .
$$

Introduzindo a variável

$$
u=1-x
$$

temos: 


$$
\begin{aligned}
& \text { - } x \sqrt{1-x}=(1-u) \sqrt{u}=(1-u) u^{1 / 2}=u^{1 / 2}-u^{3 / 2} \\
& \text { - } \frac{\mathrm{d} u}{\mathrm{~d} x}=-1 \Longrightarrow \mathrm{d} x=-\mathrm{d} u \\
& \text { - } x \sqrt{1-x} \mathrm{~d} x=\left(u^{1 / 2}-u^{3 / 2}\right)(-\mathrm{d} u)=\left(u^{3 / 2}-u^{1 / 2}\right) \mathrm{d} u
\end{aligned}
$$

Segue que

$$
F(x)=\int\left(u^{3 / 2}-u^{1 / 2}\right) \mathrm{d} u=\frac{u^{5 / 2}}{5 / 2}-\frac{u^{3 / 2}}{3 / 2}+C=\frac{2}{5}(1-x)^{\frac{5}{2}}-\frac{2}{3}(1-x)^{\frac{3}{2}}+C .
$$

Bem mais prático, não foi?

Então, resumindo, tudo o que dissemos nesta seção está contido na sentença em (11) e na ideia de que, na prática, em vez de trabalharmos, para o cálculo de $F(x)$ a partir de $f(x)$, com a expressão

$$
F(a)+\int_{a}^{x} f(t) \mathrm{d} t
$$

trabalhamos com

$$
\int f(x) \mathrm{d} x
$$

como se fosse uma integral definida, e simplesmente ignoramos os limites de integração - sem nos esquecermos de adicionar a constante arbitrária $C$ ao final. É o que se faz, na prática, e você se acostuma.

\section{Conclusão}

Se você concluiu o estudo deste material, incluindo a resolução dos exercícios, e ainda não iniciou sua primeira disciplina de cálculo, nem sua primeira disciplina de física que faz uso do cálculo, queremos lhe dizer que isso fará uma grande diferença em seu aproveitamento dessas disciplinas. Aliás, ficaremos felizes se você puder partilhar conosco sua experiência, enviandonos um e-mail. E aproveitamos para pedir que divulgue este material didático; nosso desejo é que cada estudante do ensino médio (ou equivalente) que compreenda a língua portuguesa, e que pretenda fazer um curso superior na área de física, engenharia, ou em área afim, saiba de sua existência.

Preparar este material foi uma tarefa complicada - não porque tivemos que pensar muito sobre o que incluir, mas sobre o que omitir. Você terá em sua primeira disciplina de cálculo muito mais conteúdo do que apresentamos, e provavelmente haverá uma elevação no rigor matemático, mas as ideias fundamentais estão neste texto.

\section{Agradecimentos}

Agradecemos ao professor de física Jorge Simões de Sá Martins, da UFF, e ao professor de matemática Marcilio Ferreira dos Santos, da UFPE, bem como aos pareceristas anônimos, pelas correções e por suas importantes sugestões. Agradecemos também a todos os estudantes que ajudaram a melhorar versões anteriores deste texto, através de sua participação em cursos de cálculo para pré-universitários ministrados, espaçadamente, ao longo de quase duas décadas. 


\section{Apêndice: Lista de Exercícios 23}

Exercício 1: Calcule os limites a seguir.
a) $\lim _{x \rightarrow 2} x^{3}$
b) $\lim _{x \rightarrow-2}(2 x+1)$
c) $\lim _{x \rightarrow 2} \frac{x^{2}-4}{x-2}$
d) $\lim _{t \rightarrow 5} \frac{t-5}{t^{2}-25}$
e) $\lim _{y \rightarrow \sqrt{3}} \frac{y^{2}-3}{y-\sqrt{3}}$

f) $\lim _{u \rightarrow 7} \frac{u^{2}-36}{u-6} \quad$ (Dica: no item $\mathbf{f}$ não é necessário fatorar o numerador.)

Exercício 2: No Exemplo 2 da seção "Limites de funções - uma introdução" trabalhamos com a função $f(x)=\left(x^{2}-9\right) /(x-3)$. Esboce seu gráfico e, fazendo uso dele, revise o significado de $\lim _{x \rightarrow 3}\left(x^{2}-9\right) /(x-3)=6$.

Exercício 3: Seja $L=\lim _{x \rightarrow 2}\left(x^{3}-8\right) /(x-2)$.

a) Tente encontrar o valor de $L$ fazendo uso de uma calculadora.

b) Agora, calcule esse limite analiticamente (ou seja, através de um desenvolvimento análogo ao apresentado no Exemplo 2). Sua resposta corresponde ao valor obtido na resolução do item a?

Exercício 4: A posição de uma partícula varia com o tempo de acordo com a função $s(t)=5 t^{2}$, no SI. Partindo da definição

$$
v(t)=\lim _{\Delta t \rightarrow 0} \frac{s(t+\Delta t)-s(t)}{\Delta t}
$$

calcule a velocidade da partícula:
a) para um instante $t$ qualquer;
b) para $t=2 \mathrm{~s}$.

Exercício 5: Partindo da definição, calcule a derivada de cada função a seguir.
a) $f(x)=5 x$
b) $f(x)=-3 x^{2}$
c) $f(x)=2 x^{3}$

(Dica: no item c use a identidade $(a+b)^{3}=a^{3}+3 a^{2} b+3 a b^{2}+b^{3}$.)

Exercício 6: O raio $r$ de uma circunferência varia com o tempo $t$ segundo $r=v t$, em que $v$ é a velocidade (constante) com que o raio cresce. Calcule:
a) a taxa de variação do comprimento $C$ da circunferência em relação ao tempo $t$;
b) a taxa de variação do comprimento $C$ da circunferência em relação ao raio $r$;
c) a taxa de variação da área $A$ do círculo correspondente em relação ao tempo $t$.

Exercício 7: Calcule a derivada de cada função abaixo.
a) $f(x)=7+4 x^{3}$
b) $f(x)=8 x+x^{6}$
c) $f(x)=5 x^{10}-9 x^{2}$
d) $f(x)=4 x^{-3}$
e) $f(x)=2 x+4 x^{-3}-x^{-1}$
f) $f(x)=7 / x$

Exercício 8: Calcule a derivada de cada função abaixo, inicialmente com e depois sem o uso da regra do produto. Verifique que os resultados são idênticos (como esperado).
a) $f(x)=(4 x)\left(3 x^{2}\right)$
b) $f(x)=2 x^{3}(5 x-1)$
c) $f(x)=\left(x^{2}-3 x\right)(6 x+2)$

Exercício 9: Calcule a derivada de cada função abaixo.
a) $f(x)=\frac{2 x^{3}-6 x^{2}}{2 x}$
b) $f(x)=\frac{x^{2}-4}{x-2}$
c) $f(x)=\frac{x^{2}-9}{x+3}$
d) $f(x)=\frac{2 x^{2}-4 x-6}{x+1}$

Exercício 10: Calcule $f^{\prime}(1)$ para cada função abaixo.
a) $f(x)=2 x^{3}-5 x+3$
b) $f(t)=\frac{3 t-1}{6 t^{2}+t}$
c) $f(u)=\left(9 u+6 u^{2}\right)(u+1)$

\footnotetext{
${ }^{23}$ Respostas ao final.
} 


\section{Um curso rápido de cálculo diferencial e integral para pré-universitários e calouros}

d) $f(y)=(\sqrt{3}-1)\left(y^{2}+2 y\right)$

Exercício 11: A posição de uma partícula varia com o tempo de acordo com a função

$$
s(t)=s_{0}+v_{0} t+\frac{1}{2} a t^{2},
$$

sendo $s_{0}, v_{0}$ e $a$ constantes. Calcule a velocidade dessa partícula para um instante $t$ qualquer, e dê significado às constantes $s_{0}$ e $v_{0}$ (justificando sua resposta).

Exercício 12: Usando a regra da cadeia, calcule a derivada de cada função abaixo.
a) $y=\left(4 x^{2}-1\right)^{5}$
b) $y=\frac{1}{(3 x+1)^{4}}$
c) $y=\left(\frac{x^{2}-1}{x^{2}+1}\right)^{3}$

Exercício 13: Para cada função abaixo, calcule as derivadas de ordens 1 e 2.
a) $f(x)=7 x^{2}-5 x+2$
b) $f(x)=(x-1)(x+1)$
c) $f(x)=\frac{x-1}{x+1}$

Exercício 14: Calcule a aceleração da partícula do Exercício 11, e veja por que foi escolhida a letra $a$ para a constante que multiplica $t^{2} / 2$.

Exercício 15: A posição $s$ de um certo corpo em queda livre, abandonado a partir do repouso, varia com o tempo segundo

$$
s(t)=s_{0}-\frac{1}{2} g t^{2},
$$

em que $s_{0}$ e $g$ são constantes cujos significados físicos examinaremos em um momento. Sendo $s(t)$ a altitude do corpo em relação ao solo no instante $t$, é comum trocar-se $s$ por $h$ (e $s_{0}$ por $h_{0}$ ). Temos, então,

$$
h(t)=h_{0}-\frac{1}{2} g t^{2} .
$$

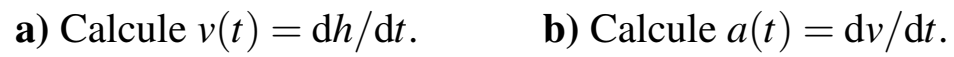

c) Quais são os significados físicos das constantes $h_{0}$ e $g$ ?

Exercício 16: Seja $f(x)=x^{3}$. Obtenha as equações das retas tangentes ao gráfico de $f$ que têm coeficiente angular igual a 3 . Se possível, use algum software para traçar, em uma mesma figura, o gráfico de $f$ e as retas tangentes cujas equações você encontrou. (Há um série de aplicativos - online ou para download - para traçar gráficos de funções; você não terá dificuldade de encontrá-los. Mas sugerimos especialmente o Geogebra.)

Exercício 17: A posição $s$ de uma partícula varia com o tempo $t$ segundo $s(t)=5 t^{4}-2 t$, com $s$ em metros e $t$ em segundos. Calcule a velocidade e a aceleração dessa partícula em função de $t$, e para $t=3 \mathrm{~s}$.

Exercício 18: O objetivo deste exercício é discutirmos os significados dos sinais da velocidade e da aceleração de uma partícula. Seja $v=\mathrm{d} s / \mathrm{d} t$. Como temos sempre $\mathrm{d} t>0$, então o sinal de $v$ é igual ao sinal de ds. Daí,

$$
\begin{aligned}
& v(t)>0 \Longrightarrow \mathrm{d} s>0 \Longrightarrow s \text { aumenta } \operatorname{com} t ; \\
& v(t)<0 \Longrightarrow \mathrm{d} s<0 \Longrightarrow s \text { diminui } \operatorname{com} t
\end{aligned}
$$

Faça uma discussão análoga sobre o sinal da aceleração instantânea. 


\section{Um curso rápido de cálculo diferencial e integral para pré-universitários e calouros}

Exercício 19: Define-se movimento uniforme (MU) como o movimento de uma partícula com velocidade constante. No MU, a posição $s$ da partícula varia com o tempo segundo

$$
s(t)=s_{0}+v t,
$$

em que $s_{0}$ e $v$ são constantes.

a) Qual é o significado físico da constante $s_{0}$ ?

b) Derivando $s$ em relação a $t$, mostre que a constante $v$ é a velocidade da partícula (e por isso foi usada a letra $v$ para aquela constante).

Exercício 20:24 Define-se movimento uniformemente variado (MUV) como o movimento de uma partícula com aceleração constante (movendo-se ao longo de uma reta). No MUV, a posição $s$ da partícula varia com o tempo segundo

$$
s(t)=s_{0}+v_{0} t+\frac{1}{2} a t^{2}
$$

em que $s_{0}, v_{0}$ e $a$ são constantes.

a) Qual é o significado físico da constante $s_{0}$ ?

b) Derivando $s$ em relação a $t$, obtenha $v(t)$ e informe o significado físico da constante $v_{0}$.

c) Derivando $v$ em relação a $t$, mostre que a constante $a$ é a aceleração da partícula.

Exercício 21: A altitude $h$ de uma partícula varia com o tempo segundo

$$
h(t)=h_{0}+v_{0} t-\frac{1}{2} g t^{2}
$$

em que $h_{0}, v_{0}$ e $g$ são constantes.

a) Quais são os significados físicos das constantes $h_{0}, v_{0}$ e $g$ ?

b) Em que instante essa partícula está parada?

c) No instante encontrado no item b, está havendo uma inversão de sentido do movimento? Discuta.

Exercício 22: Sejam $x_{A}$ e $x_{B}$ as posições - ambas funções do tempo - de duas partículas $A$ e $B$, respectivamente. A posição de $A$, relativamente a $B$, é definida como $x_{A, B}=x_{A}-x_{B}$ (faz sentido, não acha?), e a velocidade de $A$, relativamente a $B$, é a taxa de variação temporal de $x_{A, B}$, denotada por $v_{A, B}$. Mostre que $v_{A, B}=v_{A}-v_{B}$.

Exercício 23: As posições de duas partículas $A$ e $B$ variam com o tempo segundo $x_{A}(t)=$ $2 t^{3}$ e $x_{B}(t)=5+4 t$, com as posições em metros e o tempo em segundos. Calcule a velocidade de $A$, relativamente a $B$, no instante $t=2 \mathrm{~s}$.

Exercício 24: Considere uma partícula de massa $m$ movendo-se ao longo de uma reta sob a ação de uma força resultante $F_{\text {res }}$. De acordo com a segunda lei de Newton, essa partícula adquire aceleração $a=F_{\text {res }} / m$. Podemos reescrever esta igualdade como $F_{\text {res }}=m a$. O momento linear (ou a "quantidade de movimento") de uma partícula de massa $m$, e com velocidade $v$, é definido como $p=m v$. Fazendo uso desta igualdade mostre que, sendo $m$ constante, a igualdade $F_{\text {res }}=m a$ pode ser reescrita como $F_{\text {res }}=\mathrm{d} p / \mathrm{d} t \cdot 25$

Exercício 25: Se uma partícula, sob a ação de uma força $F$ (não necessariamente a força resultante), sofre um deslocamento infinitesimal $d x$ na mesma direção e no mesmo sentido da

\footnotetext{
${ }^{24}$ Já abordamos esse tipo de movimento nos Exercícios 11 e 14. Há uma repetição intencional, aqui.

${ }^{25}$ Força e aceleração, e também velocidade e momento linear (ou quantidade de movimento), são grandezas vetoriais. Estamos dispensando a notação vetorial aqui devido à restrição à trajetória retilínea.
} 


\section{Um curso rápido de cálculo diferencial e integral para pré-universitários e calouros}

força, o trabalho de $F$ ao longo do deslocamento d $x$ é, por definição, $\mathrm{d} W=F \mathrm{~d} x$. A taxa temporal de realização do trabalho, $\mathrm{d} W / \mathrm{d} t$, é denominada potência, $\mathrm{P}$. Mostre que $P=F v$.

Exercício 26: Encontre a equação da reta tangente à curva $y=\sqrt{1-x^{2}}$ no ponto de abscissa $x=\sqrt{2} / 2$. Se possível, use algum software para traçar, em uma mesma figura, aquela curva e a reta tangente cuja equação você encontrou.

Exercício 27:26 Encontre as equações de todas as retas que passam pela origem do sistema de coordenadas $x y$ e que são tangentes à curva $y=x^{2}+1$.

Exercício 28: Refaça o exercício anterior, substituindo a curva $y=x^{2}+1$ pela curva $y=(x-1)^{3}+1$.

Exercício 29: Para que valores de $x_{1}$ a reta tangente ao gráfico de $f(x)=x^{2}+1$ no ponto de abscissa $x_{1}$ é paralela à reta de equação $y=x-1$ ?

Exercício 30: Mostre que de todos os retângulos de perímetro $P$, o que possui maior área é um quadrado.

Exercício 31: Resolva novamente o problema de encontrar, dentre todos os cilindros com um determinado volume $V$, o que tem área $A$ mínima, mas desta vez expresse $A$ em função de $h$ (a altura do cilindro), em vez de $r$ (o raio do cilindro).

Exercício 32: Deseja-se fabricar um recipiente cilíndrico para armazenar $350 \mathrm{~mL}$ de refrigerante, gastando-se a menor quantidade possível de material.

a) Quais deveriam ser as dimensões desse cilindro? (Faça uso do resultado que você ja conhece - da seção "Problemas envolvendo mínimos ou máximos locais" e da resolução do Exercício 31.)

b) Latas de refrigerante possuem as dimensões que você obteve no item a? Por que será? (Esta é uma questão interessante para discussão com seus colegas. Observe, inclusive, que uma lata de refrigerante não é perfeitamente cilíndrica. Seria o fator estético importante?)

Exercício 33: De todas as latas cilíndricas abertas (ou seja, sem a "tampa superior") capazes de armazenar um mesmo volume $V$ de líquido, qual é a que possui a menor área de superfície?

Exercício 34: De todos os cilindros com uma mesma área de superfície $A$, qual é o que possui o maior volume?

Exercício 35: Chega de cilindros, não é? Vamos explorar agora uma aplicação à física. A Fig. 17 ilustra a vista superior de uma praia. No ponto $A$ encontra-se um salva-vidas, e no ponto $B$ há uma pessoa sofrendo afogamento. Talvez não seja interessante o salva-vidas seguir nadando em linha reta de $A$ até $B$, porque sua velocidade máxima na água é bem inferior à sua velocidade máxima em terra. Mas, por outro lado, qualquer outro percurso aumenta a distância total. Considere que o salva-vidas segue correndo em linha reta por terra, com velocidade $v_{1}$, do ponto $A$ ao ponto $P$, e então segue a nado em linha reta até o ponto $B$, com velocidade $v_{2}$ (sendo $v_{2}<v_{1}$, naturalmente). Encontre a posição do ponto $P$ que minimiza o tempo total. (Dica: expresse o tempo total de percurso em função de $x$, mas observe que devemos ter, com significado físico, $x \geq 0$.)

\footnotetext{
${ }^{26}$ Consideramos os exercícios 27 a 29 mais difíceis que os que você resolveu até aqui. Eles exigem bastante atenção, e uma certa organização em sua resolução. Encare esse desafio; ele será útil em sua formação.
} 


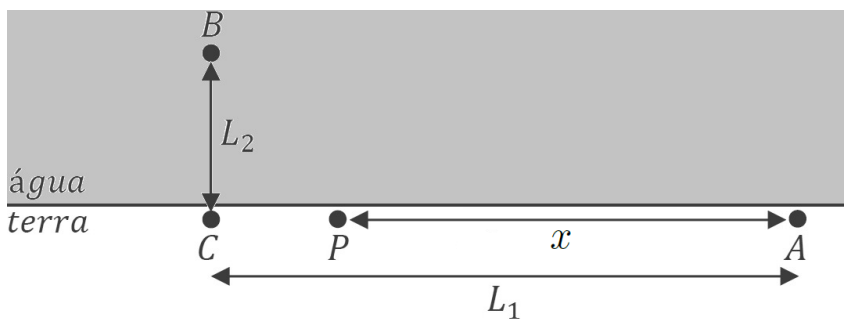

Figura 17: Exercício 35.

Exercício 36: Encontre o ponto da curva $y=\sqrt{x}$ mais próximo do ponto $(1,0)$. Se possível, use algum software para traçar aquela curva e o ponto que você encontrou, além do ponto $(1,0)$.

Exercício 37: A Fig.18 ilustra uma folha de cartolina, de dimensões originais $66 \mathrm{~cm}$ e $50 \mathrm{~cm}$, que teve seus quatro cantos recortados. Os recortes produziram quatro quadrados de lado $x$. Pretende-se construir uma caixa aberta dobrando-se a cartolina nas partes tracejadas (dobras de $90^{\circ}$ ). Calcule o valor de $x$ para que a caixa tenha o maior volume possível.

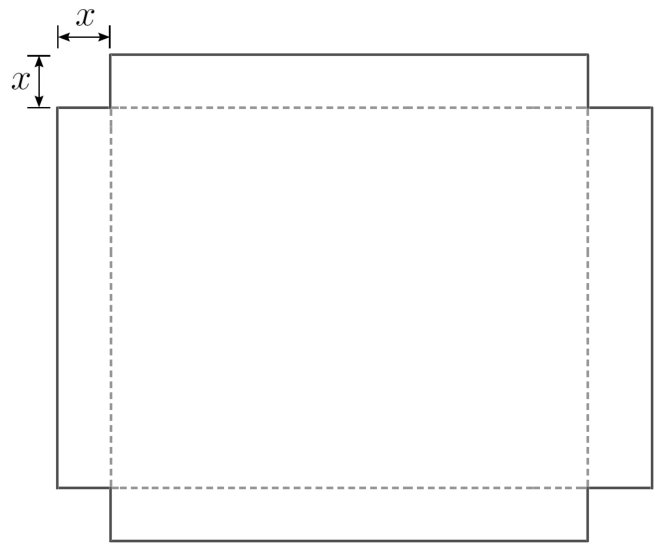

Figura 18: Exercício 37.

Exercício 38: Considere as funções $f(x)=x^{3}, g(x)=x^{4}$ e $h(x)=-x^{4}$. Todas têm primeira derivada e segunda derivada nulas para $x=0$. Então como saber se no ponto $(0,0)$ temos, para cada uma destas funções, um ponto de mínimo local, de máximo local ou de inflexão? Uma forma (que funciona bem para estas funções, que são simples) é analisar os valores de $f(x), g(x)$ e $h(x)$ na vizinhança imediata de $x=0$. Faça $x=\varepsilon$, sendo $\varepsilon$ um número positivo muito menor que 1 (escrevemos: $0<\varepsilon \ll 1$ ), e identifique, para cada uma destas funções, se $o$ ponto $(0,0)$ é um ponto de mínimo local, de máximo local ou de inflexão.

Exercício 39: Mostre que $F(x)=(x+1) /(x-1)$ é uma antiderivada de $f(x)=-2 /(x-$ $1)^{2}$. Como obter outras antiderivadas de $f(x)$ ?

Exercício 40: Obtenha, por inspeção, as antiderivadas de cada uma das funções abaixo.
a) $f(x)=-2 x$
b) $f(x)=5 x^{9}$
c) $f(x)=-x+4 x^{3}$
d) $f(x)=a x+b(a$ e $b$

constantes)

e) $f(x)=(3 x-1)^{3}$

f) $f(x)=x\left(x^{2}+2\right)$

g) $f(x)=\frac{3}{(1-x)^{3}}+5$

h) $f(x)=\frac{x-1}{\left(x^{2}-2 x\right)^{2}}+x$ 


\section{Um curso rápido de cálculo diferencial e integral para pré-universitários e calouros}

Exercício 41: A velocidade de uma partícula, movendo-se ao longo de uma reta, varia com o tempo segundo $v(t)=8 t^{3}-2 t$, com $t$ em segundos e $v$ em centímetros por segundo. Sabendo que no instante $t=0$ a partícula está na posição $s_{0}=10 \mathrm{~cm}$, obtenha $s(t)$.

Exercício 42: Uma partícula se move ao longo de uma reta com aceleração constante $a$. Sabendo que a aceleração é a derivada da velocidade $v$ em relação ao tempo, e que a velocidade é a derivada da posição $s$ em relação ao tempo, obtenha, por inspeção, $v(t)$ e, em seguida, $s(t)$. Use constantes apropriadas.

Exercício 43: Sabendo que $G(x)=(x+1) /(x-1)$ é uma antiderivada de $g(x)=-2 /(x-$ $1)^{2}$, obtenha as antiderivadas de $f(x)=1 /(x-1)^{2}$.

Exercício 44: Usando o TFC (considerando que a função $f(x)$ é contínua no intervalo $(a, b)$ ), demonstre as propriedades abaixo, da integral definida. (São propriedades intuitivas, de modo que podemos nos lembrar delas sem referência ao TFC. Por exemplo, na primeira delas estamos simplesmente pondo o fator constante $c$ em evidência, naquela "soma".)
а) $\int_{a}^{b} c f(x) \mathrm{d} x=c \int_{a}^{b} f(x) \mathrm{d} x$
b) $\int_{a}^{b}[f(x)+g(x)] \mathrm{d} x=\int_{a}^{b} f(x) \mathrm{d} x+\int_{a}^{b} g(x) \mathrm{d} x$
c) $\int_{b}^{a} f(x) \mathrm{d} x=-\int_{a}^{b} f(x) \mathrm{d} x$
d) $\int_{a}^{b} f(x) \mathrm{d} x+\int_{b}^{c} f(x) \mathrm{d} x=\int_{a}^{c} f(x) \mathrm{d} x$

Exercício 45: Calcule o trabalho da força $F(x)=15 x^{4}$, com $x$ em metros e $F$ em newtons, agindo sobre uma partícula entre as posições $x=0$ e $x=2 \mathrm{~m}$. Essa força tem a mesma direção e o mesmo sentido do deslocamento da partícula.

\section{Exercício 46:}

a) No Exemplo 4 da seção "A integral definida como uma soma" obtivemos a igualdade

$$
s=s_{0}+\int_{0}^{t} v(\tilde{t}) \mathrm{d} \tilde{t} .
$$

A partir dela obtenha a função horária da posição de uma partícula com velocidade $v$ constante:

$$
s=s_{0}+v t .
$$

Como você sabe, um movimento com velocidade constante é denominado movimento uniforme (MU).

b) Agora, considere que $s_{0}$ é a posição da partícula no instante $t=t_{0}$, em vez de no instante $t=0$. Substituindo por $t_{0}$ o limite de integração inferior na integral acima, obtenha

$$
s=s_{0}+v\left(t-t_{0}\right)
$$

\section{Exercício 47:}

a) Partindo da definição de aceleração, $a=\mathrm{d} v / \mathrm{d} t$, obtenha a igualdade

$$
v=v_{0}+\int_{0}^{t} a(\tilde{t}) \mathrm{d} \tilde{t} .
$$

b) A partir da igualdade acima, obtenha a função horária da velocidade de uma partícula com aceleração $a$ constante:

$$
v=v_{0}+a t
$$




\section{Um curso rápido de cálculo diferencial e integral para pré-universitários e calouros}

Como você sabe, um movimento com aceleração constante é denominado movimento uniformemente variado (MUV).

c) A partir da igualdade

$$
s=s_{0}+\int_{0}^{t} v(\tilde{t}) \mathrm{d} \tilde{t}
$$

obtenha a função horária da posição de uma partícula com aceleração $a$ constante:

$$
s=s_{0}+v_{0} t+\frac{1}{2} a t^{2} .
$$

d) Refaça os itens b e c considerando agora que a velocidade e a posição da partícula são $v_{0}$ e $s_{0}$ não no instante $t=0$, mas no instante $t=t_{0}$.

Exercício 48: Obtenha, por integração, as funções horárias da velocidade e da posição de uma partícula movendo-se ao longo do eixo $x$ com aceleração $a(t)=2 t^{2}$, com $t$ em segundos e $a \mathrm{em} \mathrm{m} / \mathrm{s}^{2}$, sabendo que no instante $t=0$ a partícula está na posição $5 \mathrm{~m}$, com velocidade de $3 \mathrm{~m} / \mathrm{s}$.

Exercício 49: Uma partícula se move ao longo do eixo $x$, e sobre ela age uma força $F(x)$ que tem a direção do eixo $x$. Se, para um determinado valor de $x$, temos $F(x)>0$, então o sentido dessa força é igual ao sentido do eixo $x$, e se temos $F(x)<0$, então o sentido dessa força é oposto ao sentido do eixo $x$. O trabalho de $F(x)$ entre as posições $x_{1}$ e $x_{2}$ é

$$
W=\int_{x_{1}}^{x_{2}} F(x) \mathrm{d} x
$$

Calcule o trabalho da força elástica $F_{\mathrm{el}}=-k x$ :

a) ao longo do deslocamento entre os pontos $x=0$ e $x=A$;

b) ao longo do deslocamento entre os pontos $x=A$ e $x=0$.

c) Os sinais do trabalho da força elástica nos itens a e b estão de acordo com o esperado? Discuta.

Exercício 50: Uma partícula se move ao longo do eixo $x$, e sobre ela agem $N$ forças, $F_{1}(x), F_{2}(x), \ldots, F_{N}(x)$, todas com a direção do eixo $x$. O trabalho total entre as posições $x_{1}$ e $x_{2}$ é definido como a soma dos trabalhos realizados por essas $N$ forças:

$$
W_{\text {total }}=W_{1}+W_{2}+\cdots+W_{N}=\int_{x_{1}}^{x_{2}} F_{1}(x) \mathrm{d} x+\int_{x_{1}}^{x_{2}} F_{2}(x) \mathrm{d} x+\cdots+\int_{x_{1}}^{x_{2}} F_{N}(x) \mathrm{d} x .
$$

Mostre que $W_{\text {total }}$ é igual ao trabalho da força resultante - ou seja,

$$
W_{\text {total }}=\int_{x_{1}}^{x_{2}} F_{\text {res }}(x) \mathrm{d} x
$$

em que

$$
F_{\text {res }}(x)=F_{1}(x)+F_{2}(x)+\cdots+F_{N}(x) .
$$

Exercício 51: Demonstre o teorema trabalho - energia cinética em uma dimensão:

$$
W_{\text {total }}=\Delta E_{\mathrm{c}}
$$


em que $W_{\text {total }}$ é o trabalho total realizado sobre a partícula, entre dois pontos $x_{1}$ e $x_{2}$, e $\Delta E_{\mathrm{c}}$ é a variação correspondente em sua energia cinética $E_{\mathrm{c}}=m v^{2} / 2$, sendo $m$ a massa da partícula e $v$ sua velocidade (que, em geral, não é constante).

Exercício 52: Calcule a área entre a curva $y=x^{2}$ e o eixo $x$ no intervalo $[0,1]$.

Exercício 53: Calcule a área entre as curvas $y=\sqrt{x}$ e $y=x^{2}$ no intervalo $[0,1]$. Esboce essas curvas, e destaque a região cuja área você calculou.

Exercício 54: Calcule a área da região indicada na figura abaixo.

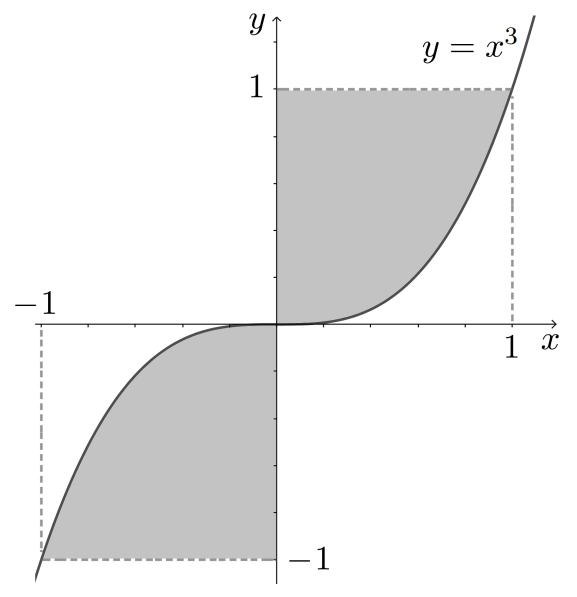

Figura 19: Exercício 54.

Exercício 55: Mostre que o volume de um cone reto de altura $H$ e base de raio $R$ é $V=\pi R^{2} H / 3$. (Dica: use o sistema de coordenadas apresentado na Fig. 20, e expresse a posição $h$ de uma fatia horizontal do cone, de altura infinitesimal $\mathrm{d} h$, em função de seu raio $r$.)

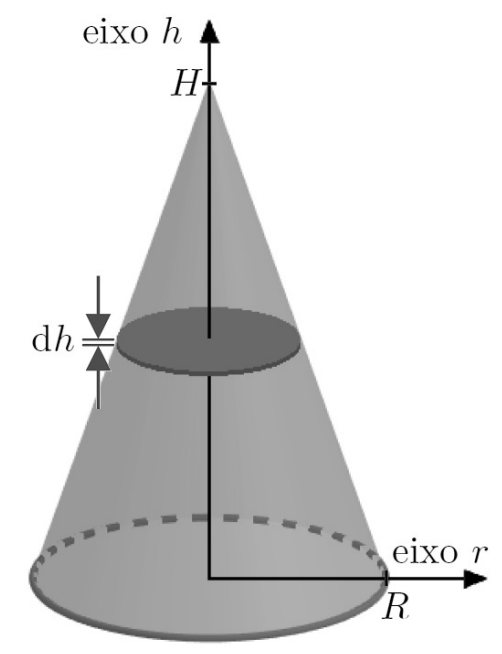

Figura 20: Exercício 55.

Exercício 56: Demonstre o teorema impulso - momento linear (ou impulso - quantidade de movimento) em uma dimensão:

$$
I_{\text {total }}=\Delta p,
$$

em que $I_{\text {total }}$ é o impulso total realizado sobre a partícula, entre dois instantes $t_{1}$ e $t_{2}$, e $\Delta p$ é a variação correspondente em seu momento linear $p=m v$, sendo $m$ a massa da partícula e $v$ sua 


\section{Um curso rápido de cálculo diferencial e integral para pré-universitários e calouros}

velocidade (que, em geral, não é constante). O impulso de uma força $F(t)$, entre dois instantes $t_{1}$ e $t_{2}$, é

$$
I=\int_{t_{1}}^{t_{2}} F(t) \mathrm{d} t .
$$

Exercício 57: Neste exercício, você irá calcular o comprimento da curva $y=x^{3 / 2}$, no intervalo $0 \leq x \leq 1$. Perceba que entre $x$ e $x+\mathrm{d} x$ temos o seguinte comprimento de curva (pela aplicação do teorema de Pitágoras): $\mathrm{d} s=\sqrt{(\mathrm{d} x)^{2}+(\mathrm{d} y)^{2}}$, que podemos reescrever como

$$
\mathrm{d} s=\sqrt{1+\left(\frac{\mathrm{d} y}{\mathrm{~d} x}\right)^{2}} \mathrm{~d} x .
$$

Exercício 58: Partindo da expressão final para a força $F$ do Exemplo 6 da seção "A integral definida como uma soma", calcule a força exercida sobre a partícula com carga elétrica $Q>0$, mas agora considerando "semi-infinita" a barra à sua esquerda - ou seja, considere que essa barra se estende, à esquerda, ao infinito. (Trata-se, é claro, de uma situação hipotética, mas que pode ser bem aproximada por uma situação real em que $L \gg D$.)

Exercício 59: Podemos pensar uma média aritmética

$$
y=\frac{y_{1}+y_{2}+\cdots+y_{N}}{N}
$$

como o caso particular de uma média ponderada

$$
y=\frac{y_{1} P_{1}+y_{2} P_{2}+\cdots+y_{N} P_{N}}{P_{1}+P_{2}+\cdots P_{N}}
$$

em que os pesos $P_{1}, P_{2}, \ldots, P_{N}$ são todos iguais, concorda? (Verifique fazendo $P_{1}=P_{2}=\cdots=$ $P_{N}=P$.)

Com isso em mente, perceba que podemos expressar o valor médio de uma função $f(x)$ no intervalo $[a, b]$ como

$$
\bar{f}_{[a, b]}=\frac{1}{b-a} \int_{a}^{b} f(x) \mathrm{d} x .
$$

Nesta expressão, temos os pesos iguais $\mathrm{d} x$, e a soma desses pesos no intervalo $[a, b]$ é

$$
\int_{a}^{b} \mathrm{~d} x=b-a .
$$

a) Calcule o valor médio de $f(x)=x$ no intervalo $[0,1]$. Foi o resultado esperado? (Veja o gráfico de $f(x)$.)

b) Calcule o valor médio de $g(x)=x^{2}$ no intervalo [0,1]. Perceba, pelos gráficos de $f(x)$ e $g(x)$, que é esperado que o valor médio de $g(x)$ seja menor que o valor médio de $f(x)$, no intervalo $[0,1]$.

Exercício 60: Você deve ter aprendido a deduzir a equação de Torricelli,

$$
v^{2}=v_{0}^{2}+2 a\left(s-s_{0}\right)
$$




\section{Um curso rápido de cálculo diferencial e integral para pré-universitários e calouros}

a partir das funções horárias do MUV,

$$
v=v_{0}+a t
$$

$\mathrm{e}$

$$
s=s_{0}+v_{0} t+\frac{1}{2} a t^{2}
$$

isolando $t$ na primeira e substituindo a expressão resultante na segunda. Neste exercício, você vai deduzir a equação de Torricelli usando cálculo integral. Partindo da definição de aceleração,

$$
a=\frac{\mathrm{d} v}{\mathrm{~d} t},
$$

podemos reescrever, se $v$ é função de $s$ :

$$
a=\frac{\mathrm{d} v}{\mathrm{~d} s} \frac{\mathrm{d} s}{\mathrm{~d} t} .
$$

Trata-se da aplicação da regra da cadeia, considerando $v$ uma função de $s-$ ou seja, considerando que para cada valor da posição $s$ da partícula há um único valor de sua velocidade $v$. Segue que

$$
a=\frac{\mathrm{d} v}{\mathrm{~d} s} v
$$

e, portanto,

$$
v \mathrm{~d} v=a(s) \mathrm{d} s .
$$

A partir desta igualdade, obtenha

$$
v^{2}=v_{0}^{2}+2 \int_{s_{0}}^{s} a(\tilde{s}) \mathrm{d} \tilde{s}
$$

e em seguida, considerando o caso particular em que a aceleração é constante, obtenha a equação de Torricelli.

\section{Respostas:}
1) a) 8 b) -3
c) 4
d) $1 / 10$
e) $2 \sqrt{3}$ f) 13

3) b) 12

4) a) $v(t)=10 t$, no SI b) $20 \mathrm{~m} / \mathrm{s}$

5) a) 5 b) $-6 x$ c) $6 x^{2}$

6) a) $2 \pi v$ b) $2 \pi$ c) $2 \pi v^{2} t$

7) a) $12 x^{2}$ b) $8+6 x^{5}$ c) $50 x^{9}-18 x$ d) $-12 x^{-4}$ e) $2-12 x^{-4}+x^{-2}$ f) $-7 / x^{2}$

8) a) $36 x^{2}$ b) $40 x^{3}-6 x^{2}$ c) $18 x^{2}-32 x-6$

9) a) $2 x-3$, para $x \neq 0$ b) 1 , para $x \neq 2$ c) 1 , para $x \neq-3$ d) 2 , para $x \neq-1$

10) a) 1 b) $-5 / 49$ c) 57 d) $4 \sqrt{3}-4$

11) $v(t)=v_{0}+a t ; v_{0}$ é a velocidade da partícula no instante $t=0$, e $s_{0}$ é a posição da partícula no instante $t=0$

12) a) $40 x\left(4 x^{2}-1\right)^{4}$ b) $-12 /(3 x+1)^{5}$ c) $12 x\left(x^{2}-1\right)^{2} /\left(x^{2}+1\right)^{4}$

13) a) $f^{\prime}(x)=14 x-5 ; f^{\prime \prime}(x)=14$ b) $f^{\prime}(x)=2 x ; f^{\prime \prime}(x)=2$ c) $f^{\prime}(x)=2 /(x+1)^{2} ; f^{\prime \prime}(x)=$ $-4 /(x+1)^{3}$

14) $a(t)=a$ (constante)

15) a) $v(t)=-g t$ b) $a(t)=-g$ c) $g$ é o módulo da aceleração do corpo, e $h_{0}$ é a altitude do 
corpo no instante $t=0$

16) $y=3 x+2, y=3 x-2$

17) $v(t)=20 t^{3}-2$, no SI; $v(3 \mathrm{~s})=538 \mathrm{~m} / \mathrm{s} ; a(t)=60 t^{2}$, no SI; $a(3 \mathrm{~s})=540 \mathrm{~m} / \mathrm{s}^{2}$

18) Seja $a=\mathrm{d} v / \mathrm{d} t$. Como temos sempre $\mathrm{d} t>0$, então o sinal de $a$ é igual ao sinal de $\mathrm{d} v$. Daí,

$$
\begin{aligned}
& a(t)>0 \Longrightarrow \mathrm{d} v>0 \Longrightarrow v \text { aumenta com } t ; \\
& a(t)<0 \Longrightarrow \mathrm{d} v<0 \Longrightarrow v \text { diminui } \operatorname{com} t .
\end{aligned}
$$

19) a) $s_{0}$ é a posição da partícula no instante $t=0$

20) a) $s_{0}$ é a posição da partícula no instante $\left.t=0 \mathrm{~b}\right) v(t)=v_{0}+a t$; $v_{0}$ é a velocidade da partícula no instante $t=0$

21) a) $h_{0}$ é a altitude da partícula no instante $t=0 ; v_{0}$ é a velocidade da partícula no instante $t=0 ; g$ é o módulo da aceleração da partícula b) $v_{0} / g$ c) sim

23) $20 \mathrm{~m} / \mathrm{s}$

26) $y=-x+\sqrt{2}$

27) $y=-2 x, y=2 x$

28) $y=3 x, y=3 x / 4$

29) $1 / 2$

32) a) diâmetro $=$ altura $\approx 7,64 \mathrm{~cm}$

33) aquela cujo diâmetro é o dobro de sua altura

34) aquele cujo diâmetro é igual à sua altura

35) se $L_{1} \geq v_{2} L_{2} / \sqrt{v_{1}^{2}-v_{2}^{2}}$ então $x=L_{1}-v_{2} L_{2} / \sqrt{v_{1}^{2}-v_{2}^{2}}$; caso contrário, $x=0$

36) $(1 / 2, \sqrt{2} / 2)$

37) $\approx 6,14 \mathrm{~cm}$

38) o ponto $(0,0)$ é, no gráfico de $f$, um ponto de inflexão; o ponto $(0,0)$ é, no gráfico de $g$, um ponto de mínimo local; o ponto $(0,0)$ é, no gráfico de $h$, um ponto de máximo local

39) Obtemos outras antiderivadas de $f(x)$ acrescentando uma constante aditiva arbitrária $C$ à expressão $(x+1) /(x-1)$ para $F(x)$

40) a) $F(x)=-x^{2}+C$ b) $F(x)=x^{10} / 2+C$ c) $F(x)=-x^{2} / 2+x^{4}+C$ d) $F(x)=a x^{2} / 2+b x+C$

e) $F(x)=(3 x-1)^{4} / 12+C$ f) $F(x)=\left(x^{2}+2\right)^{2} / 4+C$ g) $F(x)=3(1-x)^{-2} / 2+5 x+C$

h) $F(x)=-\left(x^{2}-2 x\right)^{-1} / 2+x^{2} / 2+C$

41) $s(t)=2 t^{4}-t^{2}+10$, com $s$ em cm e $t$ em s

42) $v(t)=v_{0}+a t, s(t)=s_{0}+v_{0} t+a t^{2} / 2$

43) $F(x)=-\frac{1}{2}(x+1) /(x-1)+C$

45) $96 \mathrm{~J}$

47) d) $v=v_{0}+a\left(t-t_{0}\right), s=s_{0}+v_{0}\left(t-t_{0}\right)+a\left(t-t_{0}\right)^{2} / 2$

48) $v(t)=3+2 t^{3} / 3$, no SI; $s(t)=5+3 t+t^{4} / 6$, no SI

49) a) $-k A^{2} / 2$ b) $k A^{2} / 2$ c) $\operatorname{sim}$

52) $1 / 3$

53) $1 / 3$

54) $3 / 2$

57) $\approx 1,44$

58) $K Q \lambda / D$

59) a) $1 / 2$ b) $1 / 3$ 